\title{
Sensitivity of future continental United States water deficit projections to general circulation models, the evapotranspiration estimation method, and the greenhouse gas emission scenario
}

\author{
Seungwoo Chang ${ }^{1}$, Wendy D. Graham ${ }^{1,2}$, Syewoon Hwang ${ }^{3}$, and Rafael Muñoz-Carpena ${ }^{4}$ \\ ${ }^{1}$ Department of Agricultural and Biological Engineering, University of Florida, 570 Weil Hall, \\ P.O. Box 116601, Gainesville, FL 32611, USA \\ ${ }^{2}$ Water Institute, University of Florida, 570 Weil Hall, P.O. Box 116601, Gainesville, FL 32611, USA \\ ${ }^{3}$ Department of Agricultural Engineering, Institute of Agriculture and Life Science, Gyeongsang National \\ University, Jinju, 660-701, South Korea \\ ${ }^{4}$ Department of Agricultural and Biological Engineering, University of Florida, 287 Frazier Rogers Hall, \\ P.O. Box 110570, Gainesville, FL 32611, USA
}

Correspondence to: Wendy D. Graham (wgraham@ufl.edu)

Received: 23 September 2015 - Published in Hydrol. Earth Syst. Sci. Discuss.: 15 January 2016

Revised: 21 June 2016 - Accepted: 14 July 2016 - Published: 10 August 2016

\begin{abstract}
Projecting water deficit under various possible future climate scenarios depends on the choice of general circulation model (GCM), reference evapotranspiration $\left(\mathrm{ET}_{0}\right)$ estimation method, and Representative Concentration Pathway (RCP) trajectory. The relative contribution of each of these factors must be evaluated in order to choose an appropriate ensemble of future scenarios for water resources planning. In this study variance-based global sensitivity analysis and Monte Carlo filtering were used to evaluate the relative sensitivity of projected changes in precipitation $(P), \mathrm{ET}_{0}$, and water deficit (defined here as $P-\mathrm{ET}_{0}$ ) to choice of GCM, $\mathrm{ET}_{0}$ estimation method, and RCP trajectory over the continental United States (US) for two distinct future periods: 2030-2060 (future period 1) and 2070-2100 (future period 2). A total of $9 \mathrm{GCMs}, 10 \mathrm{ET}_{0}$ methods, and $3 \mathrm{RCP}$ trajectories were used to quantify the range of future projections and estimate the relative sensitivity of future projections to each of these factors. In general, for all regions of the continental US, changes in future precipitation are most sensitive to the choice of GCM, while changes in future $\mathrm{ET}_{0}$ are most sensitive to the choice of $\mathrm{ET}_{0}$ estimation method. For changes in future water deficit, the choice of GCM is the most influential factor in the cool season (December-March), and the choice of $\mathrm{ET}_{0}$ estimation method is most important in the warm season (May-October) for all regions except the Southeast US,
\end{abstract}

where GCMs and $\mathrm{ET}_{0}$ have approximately equal influence throughout most of the year. Although the choice of RCP trajectory is generally less important than the choice of GCM or $\mathrm{ET}_{0}$ method, the impact of RCP trajectory increases in future period 2 over future period 1 for all factors. Monte Carlo filtering results indicate that particular GCMs and $\mathrm{ET}_{0}$ methods drive the projection of wetter or drier future conditions much more than RCP trajectory; however, the set of GCMs and $\mathrm{ET}_{0}$ methods that produce wetter or drier projections varies substantially by region. Results of this study indicate that, in addition to using an ensemble of GCMs and several RCP trajectories, a range of regionally relevant $\mathrm{ET}_{0}$ estimation methods should be used to develop a robust range of future conditions for water resources planning under climate change.

\section{Introduction}

Climate change will result in significant impacts on hydrologic processes. The 2014 Fifth Assessment Report (AR5) of the Intergovernmental Panel on Climate Change (IPCC) reported that climate change will significantly affect future precipitation $(P)$, temperature $(T)$, and reference evapotranspiration $\left(\mathrm{ET}_{0}\right)$, and these changes will affect the quantity and 
quality of water resources. The most recent report of the National Climate Assessment and Development Advisory Committee (NCADAC, Melillo et al., 2014) indicated that the average annual temperature in the United States (US) has increased by 0.7 to $0.9^{\circ} \mathrm{C}$ since record keeping began in 1895 and is expected to continue to rise (Georgakakos et al., 2014; Walsh et al., 2014). The NCADAC report also indicated that Coupled Model Intercomparison Project 5 (CMIP5) general circulation model (GCM) precipitation projections show a consistent increase in Alaska and the far north of the continental US and a consistent decrease in the far Southwest US, but that GCM projections are inconsistent in the precipitation transition zone of the US continent. The uncertainty in climate change projections makes actionable water resources planning difficult in many regions. In order to predict changes in the hydrologic cycle, and future water supply and demand, estimates of changes in $P, T$, and $\mathrm{ET}_{0}$ must be evaluated on a regional basis, and the uncertainty of these estimates must be quantified (Ishak et al., 2010).

Previous research has evaluated existing and potential future spatiotemporal changes in $P, T$, and $\mathrm{ET}_{0}$ for various regions around the globe (e.g., Chaouche et al., 2010; ChongHai and Ying, 2012; Johnson and Sharma, 2009; Kharin et al., 2013; Maurer and Hidalgo, 2008; Quintana Seguí et al., 2010; Sung et al., 2012; Thomas, 2000; Wang et al., 2013; Xu et al., 2006). It is well known that future GCM projections of temperature and precipitation vary significantly due to both the different radiative forcing assumptions of carbon dioxide scenarios (e.g., the CMIP3 Special Report on Emissions Scenarios (SRES) and CMIP5 Representative Concentration Pathways; RCP trajectories) and different GCM model physics (Hawkins and Sutton, 2009, 2010). Future $\mathrm{ET}_{0}$ projections have been shown to depend on $\mathrm{ET}_{0}$ estimation methods in addition to GCMs. For example, Wang et al. (2015) used projections from the CMIP3 HADCM3 model A2 scenario and found that the physically based Penman-Monteith equation, which uses less reliable GCM projection data (including vapor pressure and solar radiation), and the empirical temperature-based Hargreaves equation showed similar patterns but different magnitudes for future $\mathrm{ET}_{0}$ changes over the Hanjiang River basin in China. Kingston et al. (2009) used five GCMs from the CMIP3 climate projections and six different $\mathrm{ET}_{0}$ equations to estimate global $\mathrm{ET}_{0}$ and found that the choice of $\mathrm{ET}_{0}$ method contributes to different projections of the future state of water resources, which varies by region. They found that the Hamon and Jensen-Haise $\mathrm{ET}_{0}$ estimates showed the greatest changes in both humid and arid regions, while the Penman-Monteith and Priestley-Taylor estimates frequently showed the smallest change. Similarly, McAfee (2013) used three $\mathrm{ET}_{0}$ equations with 17 CMIP3 GCMs to evaluate the uncertainty of future global $\mathrm{ET}_{0}$ projections and found that the Hamon equation showed more significant and consistently positive trends in $\mathrm{ET}_{0}$ compared to the Priestley-Taylor and Penman methods.

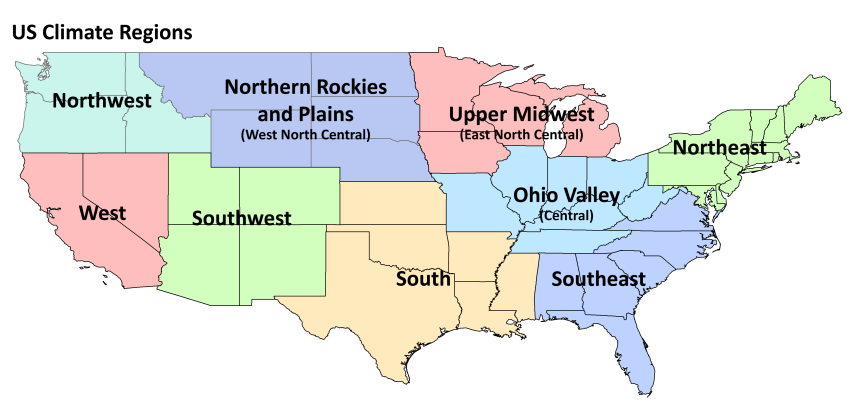

Figure 1. US climate regions identified by the National Climate Data Center (adapted from Karl and Koss, 1984, https://www.ncdc. noaa.gov/monitoring-references/maps/us-climate-regions.php).

Models developed to estimate future water supply and demand as a result of projected climate change use many different types of $\mathrm{ET}_{0}$ estimation methods (Zhao et al., 2013). Because the choice of $\mathrm{ET}_{0}$ estimation method may be as important as the choice of GCM or RCP trajectory, better understanding of the contribution of each of these factors to the overall prediction uncertainty of future water availability or water deficit is necessary (Taylor et al., 2013). Kay and Davies (2008) compared the performance of the Penman-Monteith equation and a simple temperature-based $\mathrm{ET}_{0}$ method using climate data from five global and eight regional climate models over Britain. They found that the two methods showed very different changes in $\mathrm{ET}_{0}$ for the period 2071-2100 under the A2 emission scenario and different flow predictions for three catchments when the data were used to force a rainfall-runoff model. Kay and Davies results suggest that hydrological prediction uncertainty due to $\mathrm{ET}_{0}$ formulation was smaller than that due to GCM structure or RCM structure for their study region. Bae et al. (2011) evaluated the uncertainty contributed by choice of GCM and hydrologic model for the Chungju Dam basin, Korea. They found that hydrologic model structural differences contributed greater uncertainty than GCM selection to winter runoff prediction. Koedyk and Kingston (2016) found that for the Waikaia River, New Zealand, the $\mathrm{ET}_{0}$ method contributed more uncertainty than GCM selection when predicting $\mathrm{ET}_{0}$, but that runoff predictions were more sensitive to GCMs than to $\mathrm{ET}_{0}$ methods. Thompson et al. (2014) evaluated the effect of using different GCMs and different $\mathrm{ET}_{0}$ methods on discharge predictions for the Mekong River in Southeast Asia and found that GCM-related uncertainty was greater than the $\mathrm{ET}_{0}$ method-related uncertainty.

In this study we perform a comprehensive evaluation of the relative sensitivity of future $P, \mathrm{ET}_{0}$, and water deficit (defined here as $P-\mathrm{ET}_{0}$ ) projections to the choice of GCM, $\mathrm{ET}_{0}$ method, and RCP trajectory over the continental USA using CMIP5 GCM model outputs to provide new insights that will inform more robust future water resources planning efforts. Variance-based global sensitivity analysis (Saltelli et al., 2010) and Monte Carlo filtering (Rose et al., 1991) are 
Table 1. Description of reference evapotranspiration estimation methods used in this study (ET ${ }_{0}$ : reference evapotranspiration).

\begin{tabular}{lll}
\hline Methods & Equations $^{1}$ & Reference \\
\hline (a) Hargreaves & $\mathrm{ET}_{0}=0.0135 K_{T} S_{0}(T+17.8) \sqrt{\delta_{T}}$ & Hargreaves and Allen (2003) \\
(b) Blaney-Criddle & $\mathrm{ET}_{0}=p(0.46 T+8.13)$ & Xu and Singh (2002) \\
(c) Hamon & $\mathrm{ET}_{0}=0.55 \delta_{T}^{2} P_{t}$ & Xu and Singh (2002) \\
(d) Kharrufa & $\mathrm{ET}_{0}=0.34 p T^{1.3}$ & Xu and Singh (2002) \\
(e) Irmak-Rn & $\mathrm{ET}_{0}=0.486+0.289 R_{\mathrm{n}}+0.023 T$ & Irmak et al. (2003) \\
(f) Irmak-Rs & $\mathrm{ET}_{0}=-0.611+0.149 R_{\mathrm{S}}+0.079 T$ & Irmak et al. (2003) \\
(g) Dalton & $\mathrm{ET}_{0}=(0.3648+0.07223 u)\left(e_{\mathrm{S}}-e_{\mathrm{a}}\right)$ & Tabari et al. (2013) \\
(h) Meyer & $\mathrm{ET}_{0}=(0.375+0.05026 u)\left(e_{\mathrm{S}}-e_{\mathrm{a}}\right)$ & Tabari et al. (2013) \\
(i) Penman-Monteith & $\mathrm{ET}_{0}=\frac{0.408 \Delta\left(R_{\mathrm{n}}-G\right)+\gamma \frac{900}{T+273} u_{2}\left(e_{\mathrm{s}}-e_{\mathrm{a}}\right)}{\Delta+\gamma\left(1+0.34 u_{2}\right)}$ & Allen et al. (1998) \\
(j) Priestley-Taylor & $\mathrm{ET}_{0}=\alpha \frac{\Delta}{\Delta+\gamma} \frac{\left(R_{\mathrm{n}}-G\right)}{\lambda}$ & Allen et al. (1998) \\
\hline
\end{tabular}

\footnotetext{
1 Variables (estimated from CMIP5 outputs): $G$ : soil heat flux (assumed 0); $\gamma$ : psychrometric constant; $T$ : average temperature $u_{2}$ : wind speed at $2 \mathrm{~m}$ surface; $e_{\mathrm{s}}$ : saturated vapor pressure; $e_{\mathrm{a}}$ : actual vapor pressure; $\Delta$ : slope vapor pressure; $\mathrm{K}_{T}$ :

Hargreaves-Samani coefficient; $S_{0}$ : extraterrestrial radiation (estimated by Julian date); $\delta_{T}$ : difference between maximum and minimum temperature, $p$ : percentage of total daytime hours (estimated by Julian date); $R_{\mathrm{n}}$ : net radiation; $R_{\mathrm{S}}$ : solar radiation;

$P_{t}$ : saturated water vapor density; $u$ : wind speed.
}

used to quantify the uncertainty and important input factors controlling these projections. Global sensitivity analysis (GSA) apportions the total output uncertainty simultaneously onto all the uncertain input factors described by marginal probability density functions, and thus is preferred over the local, one factor at a time, sensitivity analyses that have been previously reported (Homma and Saltelli, 1996; Saltelli, 1999). Monte Carlo filtering can identify sets of model simulations and input factors that meet a specified criterion or threshold. Thus global sensitivity analysis and Monte Carlo filtering offer an opportunity to gain insight into the sources of uncertainty and drivers of particular types of wet/dry behavior when estimating future water deficit under projected climate change.

\section{Methods}

All retrospective and future climate variables were obtained from the CMIP5 archive (accessible for download at http: //pcmdi9.1lnl.gov/). The "historical" runs of CMIP5 were used for the retrospective period (1950-2005) and the same ensemble member runs (r1i1p1 ensemble) of CMIP5 were used for two future periods: future period 1 (2030-2060), and future period 2 (2070-2100). Data for three RCP trajectories, RCP2.6, RCP4.5, and RCP8.5, were included in the analyses. Taylor et al. (2012) described an overview of CMIP5 and RCP trajectories and compared the differences between CMIP5 and CMIP3 model projections.

Data from the CMIP5 archive were used to calculate monthly mean $P, \mathrm{ET}_{0}$, and $P-\mathrm{ET}_{0}$ (water deficit) for the retrospective and both future periods over each of the nine US climate regions identified by the National Climatic Data Center (Karl and Koss, 1984; Fig. 1). Future changes in monthly mean $P, \mathrm{ET}_{0}$, and $P-\mathrm{ET}_{0}$ were estimated by subtracting the monthly mean value for the retrospective period from the monthly mean value for future period 1 or future period 2 , as appropriate (Baker and Huang, 2014).

Ten commonly used reference evapotranspiration estimation methods (Hargreaves, Blaney-Criddle, Hamon, Kharrufa, Irmak-Rn, Irmak-Rs, Dalton, Meyer, PenmanMonteith, and Priestley-Taylor) were used in this study. The methods can be further classified into temperature (Hargreaves, Blaney-Criddle, Hamon, and Kharrufa), radiation (Irmak-Rn, Irmak-Rs, and Priestley-Taylor), mass transfer (Dalton and Meyer), and combination (Penman-Monteith) equations. These equations are well described in many papers (e.g., Allen et al., 1998; Hargreaves and Allen, 2003; Irmak et al., 2003; Tabari, 2010; Tabari et al., 2013; Xu and Singh, 2001) and are summarized in Table 1 (hereafter precipitation is referred to as $P$, and reference evapotranspiration is referred to as $\mathrm{ET}_{0}$ for convenience).

Variables directly used from the CMIP5 monthly model output included precipitation (pr, $P$ in this study), maximum and minimum temperature (tasmax and tasmin), radiation (rlds, rlus, rsds, and rsus), air pressure (psl and ps), and wind speed (sfcWind). The abbreviations for these variables are as defined in the CMIP5 archive and explained in the PCMDI server (Program For Climate Model Diagnosis and Intercomparison, http://cmip-pcmdi.llnl.gov/cmip5/ docs/standard_output.pdf). Other variables needed in the 10 reference evapotranspiration equations were calculated using the variables from CMIP5 monthly model output (for details, see Table 1). Monthly output that included all the variables needed for the Penman-Monteith reference evapotranspiration method (the most data-intensive method) was available for both the retrospective period and for the RCP2.6, RCP 4.5, and RCP8.5 trajectories for the future periods, for nine CMIP5 models. Table 2 lists the nine models from the CMIP5 archive that were used in this study. 
Table 2. Description of the CMIP5 models used in this study.

\begin{tabular}{|c|c|c|c|c|c|}
\hline Model & Institute (country) & \multicolumn{2}{|c|}{ Resolutions } & Calendar & Reference \\
\hline (1) BNU-ESM & $\begin{array}{l}\text { College of Global Change and Earth } \\
\text { System Science, Beijing Normal } \\
\text { University (China) }\end{array}$ & \multicolumn{2}{|c|}{$2.8^{\circ}$ lat $\times 2.8^{\circ}$ lon } & No leap & Ji et al. (2014) \\
\hline (2) CSIRO-MK3-6-0 & $\begin{array}{l}\text { University of New South } \\
\text { Wales (Australia) }\end{array}$ & \multicolumn{2}{|c|}{$1.87^{\circ}$ lat $\times 1.87^{\circ}$ lon } & No leap & Rotstayn et al. (2012) \\
\hline (3) GFDL-CM3 & $\begin{array}{l}\text { NOAA/Geophysical Fluid } \\
\text { Dynamics Laboratory (USA) }\end{array}$ & $2.0^{\circ}$ lat $\times$ & $2.5^{\circ}$ lon & No leap & Guo et al. (2014) \\
\hline (4) GFDL-ESM2G & $\begin{array}{l}\text { NOAA/Geophysical Fluid } \\
\text { Dynamics Laboratory (USA) }\end{array}$ & $2.0^{\circ}$ lat $\times$ & $2.5^{\circ}$ lon & No leap & Taylor et al. (2012) \\
\hline (5) MIROC-ESM & $\begin{array}{l}\text { Atmosphere and Ocean Research } \\
\text { Institute, National Institute for } \\
\text { Environmental Studies, and Japan } \\
\text { Agency for Marine-Earth Science and } \\
\text { Technology (Japan) }\end{array}$ & $2.8^{\circ}$ lat $\times$ & $2.8^{\circ}$ lon & Leap year & Watanabe et al. (2011) \\
\hline (6) MPI-ESM-LR & $\begin{array}{l}\text { Max Planck Institute for } \\
\text { Meteorology (Germany) }\end{array}$ & $1.87^{\circ}$ lat $\times$ & $1.87^{\circ}$ lon & Leap year & Block and Mauritsen (2013) \\
\hline (7) MRI-CGCM3 & $\begin{array}{l}\text { Meteorological Research } \\
\text { Institute (Japan) }\end{array}$ & $1.12^{\circ}$ lat $\times$ & $1.12^{\circ}$ lon & Leap year & Yukimoto et al. (2012) \\
\hline (8) NorESM1-M & $\begin{array}{l}\text { Norwegian Climate } \\
\text { Centre (Norway) }\end{array}$ & $1.9^{\circ}$ lat $\times$ & $2.5^{\circ}$ lon & No leap & Bentsen et al. (2013) \\
\hline (9) BCC-CSM1.1 & Beijing Climate Center (China) & $2.8^{\circ}$ lat $\times$ & $2.8^{\circ}$ lon & No leap & Xiao-Ge et al. (2013) \\
\hline
\end{tabular}

The sensitivity of changes in future $P, \mathrm{ET}_{0}$, and water deficit (defined here as $P-\mathrm{ET}_{0}$ ) to the choice of GCM, $\mathrm{ET}_{0}$ estimation method, and RCP trajectory was evaluated using the variance-based GSA method of Saltelli et al. (2010). Given a model of the form $Y=f\left(X_{1} X_{2}, \ldots X_{k}\right)$, with $Y$ a scalar, the variance-based first-order effect for a generic factor $X_{i}$ can be written as (Saltelli et al., 2010)

$V_{X_{i}}\left(E_{\boldsymbol{X}_{\sim i}}\left(Y \mid X_{i}\right)\right)$

where $X_{i}$ is the $i$ th factor (in our case either GCMs, $\mathrm{ET}_{0}$ method, or RCP trajectory) and $\boldsymbol{X}_{\sim i}$ is the vector of all factors except $X_{i}$. The expectation operator $E_{\boldsymbol{X}_{\sim i}}\left(Y \mid X_{i}\right)$ indicates that the mean of $Y$ is taken over all possible values of $X$ except $X_{i}$ (i.e., $\boldsymbol{X}_{\sim i}$ ) while keeping $X_{i}$ fixed. The variance, $V_{X_{i}}$, is then taken of this quantity over all possible values of $X_{i}$.

The first-order sensitivity coefficient is expressed as

$S_{i}=\frac{V_{X_{i}}\left(E_{X_{\sim i}}(Y \mid X)\right)}{V(Y)}$,

where $V(Y)$ is the total variance of $Y$ over all $X_{i} . S_{i}$ is a normalized index varying between 0 and 1 , because $V_{X_{i}}\left(E_{X_{\sim i}}\left(Y \mid X_{i}\right)\right)$ varies between 0 and $V(Y)$ according to the identity (Mood et al., 1974)

$V_{X_{i}}\left(E_{\boldsymbol{X}_{\sim i}}\left(Y \mid X_{i}\right)\right)+E_{X_{i}}\left(V_{\boldsymbol{X}_{\sim i}}\left(Y \mid X_{i}\right)\right)=V(Y)$.

As indicated above, $V_{X_{i}}\left(E_{\boldsymbol{X}_{\sim i}}\left(Y \mid X_{i}\right)\right)$ is the first-order effect of $X_{i}$ on the model output $Y$, while $E_{X_{i}}\left(V_{X_{\sim i}}\left(Y \mid X_{i}\right)\right)$ is called the residual. The total effect index, including firstorder and higher-order effects (i.e., interactions between factor $X_{i}$ and other factors) of the factor $X_{i}$ on the model output is calculated (Saltelli et al., 2010):

$S_{T_{i}}=\frac{E_{\boldsymbol{X}_{\sim i}}\left(V_{X_{i}}\left(Y \mid \boldsymbol{X}_{\sim i}\right)\right)}{V(Y)}=1-\frac{V_{\boldsymbol{X}_{\sim i}}\left(E_{X_{i}}\left(Y \mid \boldsymbol{X}_{\sim i}\right)\right)}{V(Y)}$.

The first-order sensitivity of estimated future changes in mean monthly $P, \mathrm{ET}_{0}$, and $P-\mathrm{ET}_{0}$ to choice of GCM, $\mathrm{ET}_{0}$ estimation method, and RCP trajectory was calculated over the nine US climate regions for each future period in order to evaluate the relative contributions of each of these factors in the uncertainty of future changes. A total of 270 simulations $(9 \mathrm{GCMs} \times 10$ evapotranspiration methods $\times 3 \mathrm{RCP}$ trajectories) was used in the analysis. Sensitivity of projected changes in $P$ was evaluated for both choice of GCM and choice of RCP trajectory. Sensitivity of projected changes in $\mathrm{ET}_{0}$ and $P-\mathrm{ET}_{0}$ was evaluated for choice of GCM, choice of $\mathrm{ET}_{0}$ estimation method, and choice of RCP trajectory.

For projected changes in water deficit $\left(P-\mathrm{ET}_{0}\right)$, Monte Carlo filtering (Saltelli et al., 2008) was used to identify whether projected wetter or drier future conditions (i.e., larger or smaller water deficit) could be attributed to specific GCMs, $\mathrm{ET}_{0}$ estimation methods, or RCP trajectories. For each future period the ensemble of 270 projections of change in water deficit were categorized as either wet future condition (mean change in $\left.\left(P-E T_{0}\right) \geq 0\right)$ or dry future condition (mean change in $\left(P-E T_{0}\right)<0$ ). Next for each factor $\left(X_{i}=\mathrm{GCM}, \mathrm{ET}_{0}\right.$ method, RCP trajectory), the histograms of wet $\left(f_{\text {wet }} \mid X_{i}\right)$ and dry $\left(f_{\text {dry }} \mid X_{i}\right)$ future condi- 


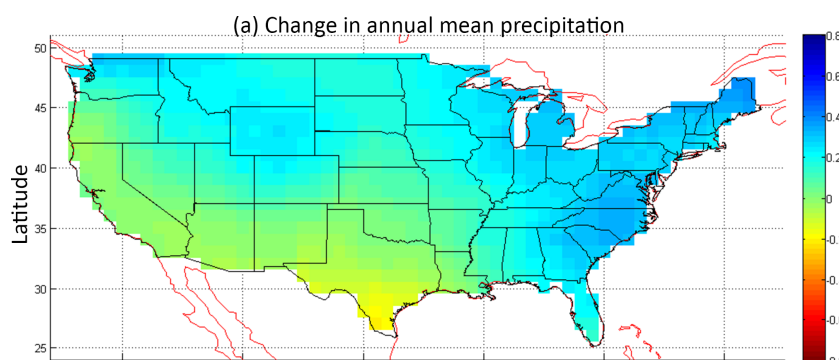

(b) Change in annual mean reference evapotranspiration

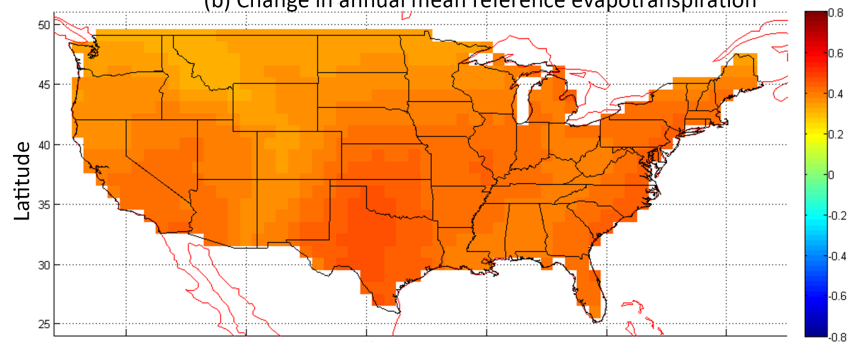

(c) Change in annual mean water deficit

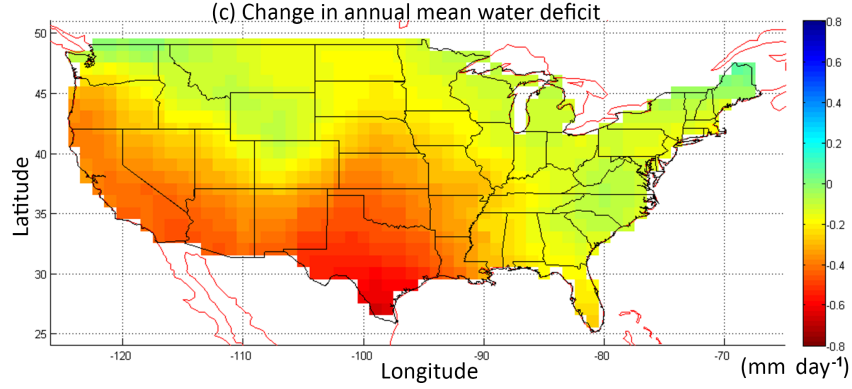

Figure 2. The change in the annual mean (a) $P$, (b) $\mathrm{ET}_{0}$, and (c) $P$ $\mathrm{ET}_{0}$ over the US. All units are mm day ${ }^{-1}$ and the change is defined as the mean of 2070-2100 minus that of 1950-2005. These changes are averaged over all GCMs, $\mathrm{ET}_{0}$ estimation methods, and RCP trajectories.

tions over the range of possible values of that factor were estimated. To identify the factors that are most responsible for driving the model into projected wet or dry future conditions for each factor, $X_{i}$, the distributions $\left(f_{\text {wet }} \mid X_{i}\right)$ and $\left(f_{\text {dry }} \mid X_{i}\right)$ were tested for significant difference using the $X^{2}$ two-sample test for categorical variables with $\alpha=0.05$ (Rao and Scott, 1981). If for a given factor $X_{i}$ the two distributions are significantly different, then $X_{i}$ is a key factor in driving into either a wet or dry condition (Saltelli et al., 2008).

Because GCM predictions are known to contain systematic biases (Hwang and Graham, 2013; Wood et al., 2002, 2004), we evaluated the sensitivity of the mean monthly change in raw climate predictions between retrospective and future periods to the choice of GCM, $\mathrm{ET}_{0}$ estimation method, and RCP trajectories. This is analogous to using the delta change GCM bias-correction method that involves shifting the mean of a series of observed climate data by the mean difference in raw GCM output between the corresponding observed time period and the desired future period. Teutschbein and Seibert (2012) pointed out that all bias-correction methods are based on the stationarity principle that assumes that (a) SD of change in annual mean precipitation

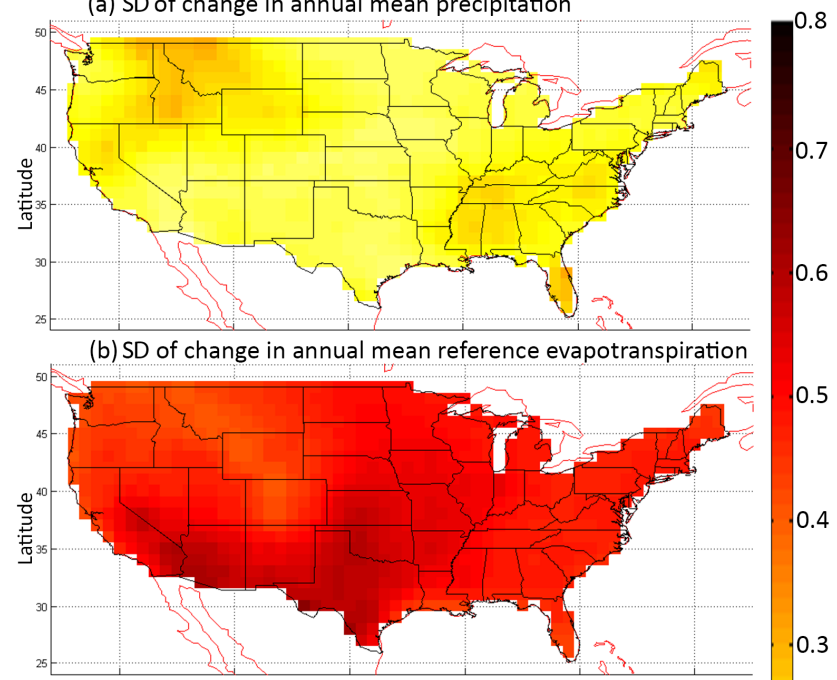

(c) SD of change in annual mean water deficit

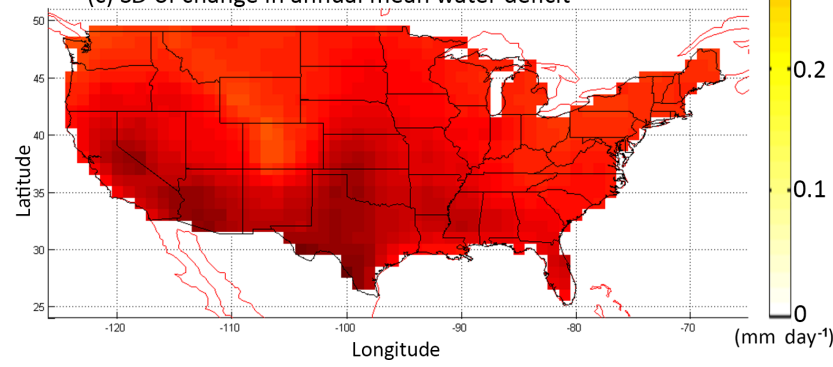

Figure 3. The standard deviation of the change in the annual mean (a) $P$, (b) $\mathrm{ET}_{0}$, and (c) $P-\mathrm{ET}_{0}$ over the US. All units are $\mathrm{mm} \mathrm{day}^{-1}$ and the change is defined as the average of 2070-2100 minus that of 1950-2005. The standard deviations are estimated over all GCMs, $\mathrm{ET}_{0}$ estimation methods, and RCP trajectories.

similar biases occur in the retrospective and future predictions, and thus the same bias-correction algorithm may be applied to both. Muerth et al. (2013) found that the impact of bias correction on the relative change of flow indicators between retrospective and future periods was weak for most indicators; however, Pierce et al. (2015) found that some bias-correction methods altered model-projected changes in mean precipitation and temperature. LaFond et al. (2014) found that the delta change GCM bias-correction method was more useful for simulating hydrologic extreme events than the quantile mapping bias-correction method, as it preserved daily climate variability better. In this study, we differenced raw rather than bias-corrected GCM outputs in order to prevent spurious alteration of the climate change signal between retrospective and future GCMs that might be induced by the bias-correction method. 

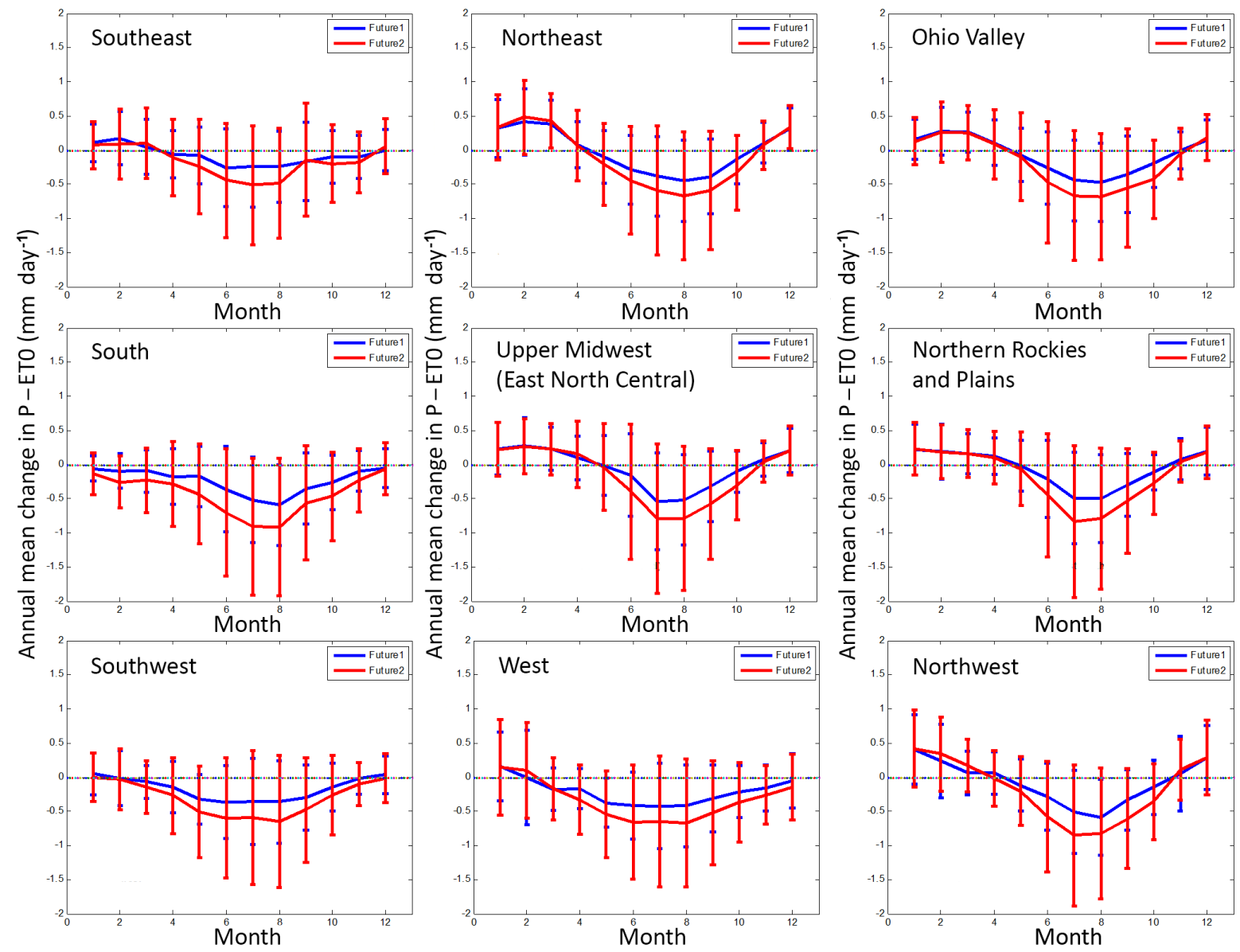

Figure 4. The change in monthly mean water deficit $\left(P-\mathrm{ET}_{0}\right)$ over nine different regions. Blue lines represent future period 1 (2030-2060), and red lines represent future period 2 (2070-2100). Error bars represent 1 standard deviation of each value. The change is defined as the mean of future periods minus that of retrospective periods (1950-2005).

\section{Results}

\subsection{Projected $P, \mathrm{ET}_{0}$, and water deficit change in the 21st century}

Future $P, \mathrm{ET}_{0}$, and water deficit projections include large uncertainties stemming from different sources. Figures 2 and 3 present maps of the mean change (Fig. 2) and the standard deviation of change (Fig. 3) in annual $P$ (top chart), $\mathrm{ET}_{0}$ (middle), and water deficit $\left(P-\mathrm{ET}_{0}\right.$; bottom) over the continental US calculated over all GCMs, $\mathrm{ET}_{0}$ estimation methods, and RCP trajectories for future period 2 (2070-2100). Major portions of the West, Southwest, and South show a mean decrease in annual precipitation, while the rest of the continental US shows a mean increase (Fig. 2a). Future annual $\mathrm{ET}_{0}$ shows a mean increase over retrospective annual $\mathrm{ET}_{0}$ over the entire US (Fig. 2b), with the largest increase in the South region. Following the patterns of $P$ and $\mathrm{ET}_{0}$, future annual water deficit $\left(P-\mathrm{ET}_{0}\right)$ shows a significant mean decrease in the West, Southwest, and South regions, and a slight decline or negligible change in most other regions (Fig. 2c). These mean changes in annual $P, \mathrm{ET}_{0}$, and $P-\mathrm{ET}_{0}$ are relatively small compared to the standard deviation of changes in annual $P, \mathrm{ET}_{0}$, and $P-\mathrm{ET}_{0}$ (Fig. 3). Water deficit in particular has a large standard deviation, resulting in coefficients of variation larger than 1 throughout the continental US. Similar results are shown in Figs. S1 and S2 for future period 1 (2030-2060) in the Supplement.

Figure 4 shows the seasonal changes in the monthly mean and standard deviation of water deficit $\left(P-\mathrm{ET}_{0}\right)$ over the nine US regions. Blue and red lines represent the changes in monthly mean water deficit for future period 1 and future period 2, respectively, and the error bars represent 1 standard deviation around each mean value. All regions of the continental US show drier conditions (negative mean changes) in the summer season (June-August). Southern regions (Southeast, South, Southwest, and West) show drier conditions throughout the year; however, northern portions of the US (i.e., the Northeast, Ohio Valley, Upper Midwest, 

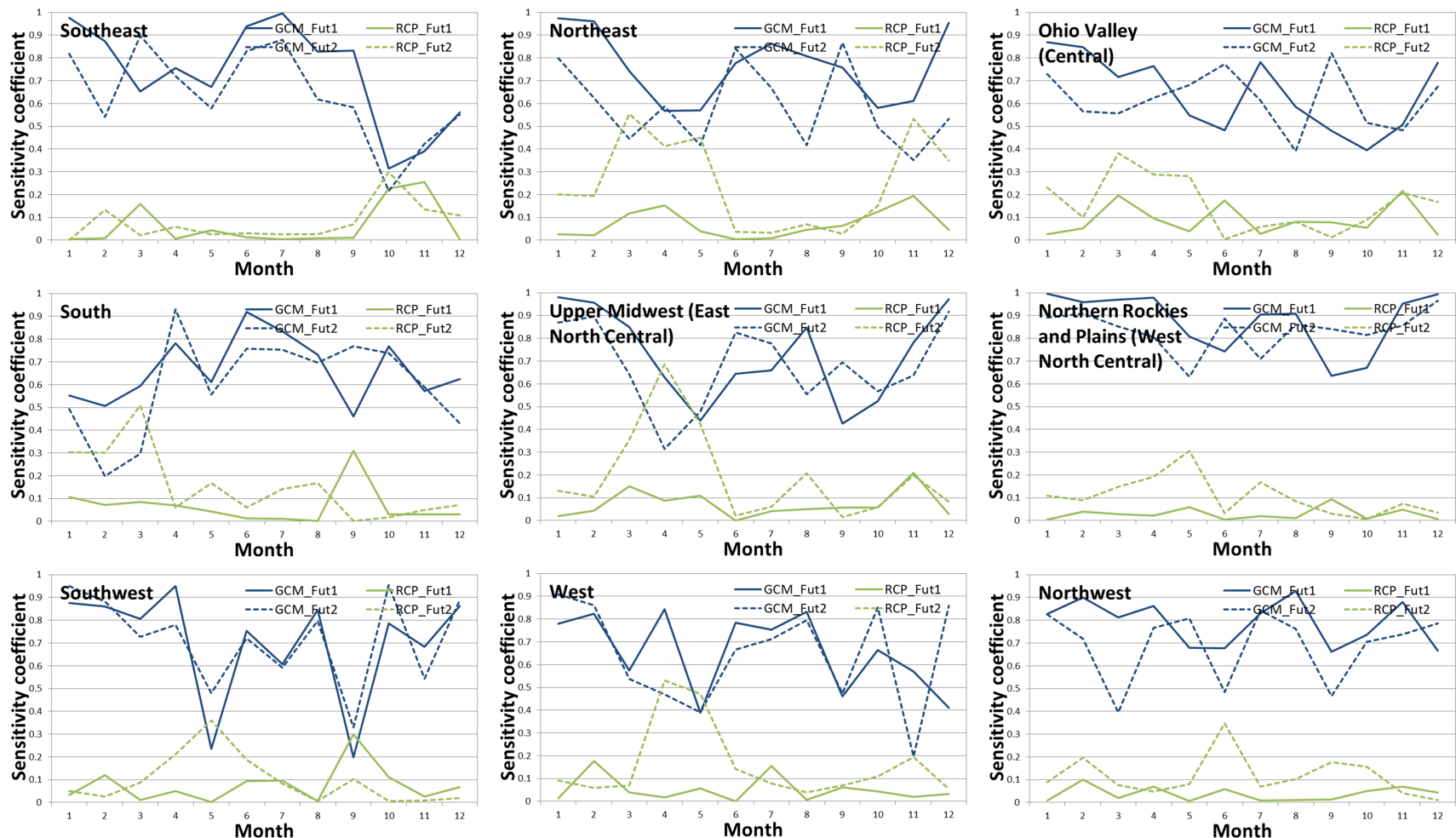

Figure 5. First-order sensitivity analysis results of change in precipitation. Solid lines represent future period 1 (2030-2060) and dotted lines represent future period 2 (2070-2100). Blue lines represent the first-order effect of GCMs and green lines represent the first-order effect of RCPs.

Northern Rockies and Plains, and Northwest) show wetter conditions (positive mean changes) in the winter season.

\subsection{Global sensitivity analysis of projected changes}

Figure 5 shows the first-order sensitivity of change in $P$ to GCMs and RCP trajectory over the nine US climate regions for future periods 1 and 2 . For projected changes in $P$, the choice of GCM is generally more important than the choice of RCP trajectory for all regions and both future periods. First-order sensitivities of mean change in $\mathrm{ET}_{0}$ to GCM, $\mathrm{ET}_{0}$ method, and RCP trajectory are shown in Fig. 6. This figure clearly shows that the choice of $\mathrm{ET}_{0}$ method is the most influential factor for projecting change in $\mathrm{ET}_{0}$ for both future periods, except for the month of March in the Northeast, Upper Midwest, and Northern Rockies and Plains. High sensitivity of mean change in $\mathrm{ET}_{0}$ to GCM selection occurs in spring for several regions (Northeast, Upper Midwest, and Northern Rockies and Plains), indicating a divergence of model predictions during this time. The influence of the RCP trajectory on $\mathrm{ET}_{0}$ increases in future period 2 over future period 1, with a concomitant decrease in the influence of both $\mathrm{ET}_{0}$ method and GCM. In future period 1 the GCM sensitivity coefficients are greater than the RCP trajectory sensitivity coefficients over most regions; however, in future period 2 the RCP sensitivity coefficients become more impor- tant. Figure 7 shows that projected change in water deficit depends strongly on both the choice of GCM and $\mathrm{ET}_{0}$ estimation method. In all regions except the Southeast, projected change in water deficit is most sensitive to $\mathrm{ET}_{0}$ estimation method in the warm season (May through October) and most sensitive to GCM in the cool season (December through March). For the Southeast region, the sensitivity coefficients for GCM and $\mathrm{ET}_{0}$ method are quite similar throughout the year. The sensitivity coefficients for RCP trajectory are very low in future period 1 , but increase in future period 2 , becoming approximately equal to the GCM sensitivity coefficients in the summer season in future period 2.

\subsection{Change in annual mean water deficit projections using different $\mathrm{ET}_{0}$ methods}

Figure 8 shows the change in annual mean water deficit over all nine GCMs for the RCP 4.5 trajectory in future period 1 (2030-2060) predicted by the 10 different $\mathrm{ET}_{0}$ methods used in this study (a: Hargreaves; b: Blaney-Criddle; c: Hamon; d: Kharrufa; e: Irmak-Rn; f: Irmak-Rs; g: Dalton; h: Meyer; i: Penman-Monteith; j: Priestley-Taylor). This figure clearly shows that the changes in water deficit for future period 1 are diverse and depend strongly on the choice of $\mathrm{ET}_{0}$ method. Except for the Hargreaves method (Fig. 8a), the temperature-based methods (e.g., Blaney-Criddle, Fig. 8b; 

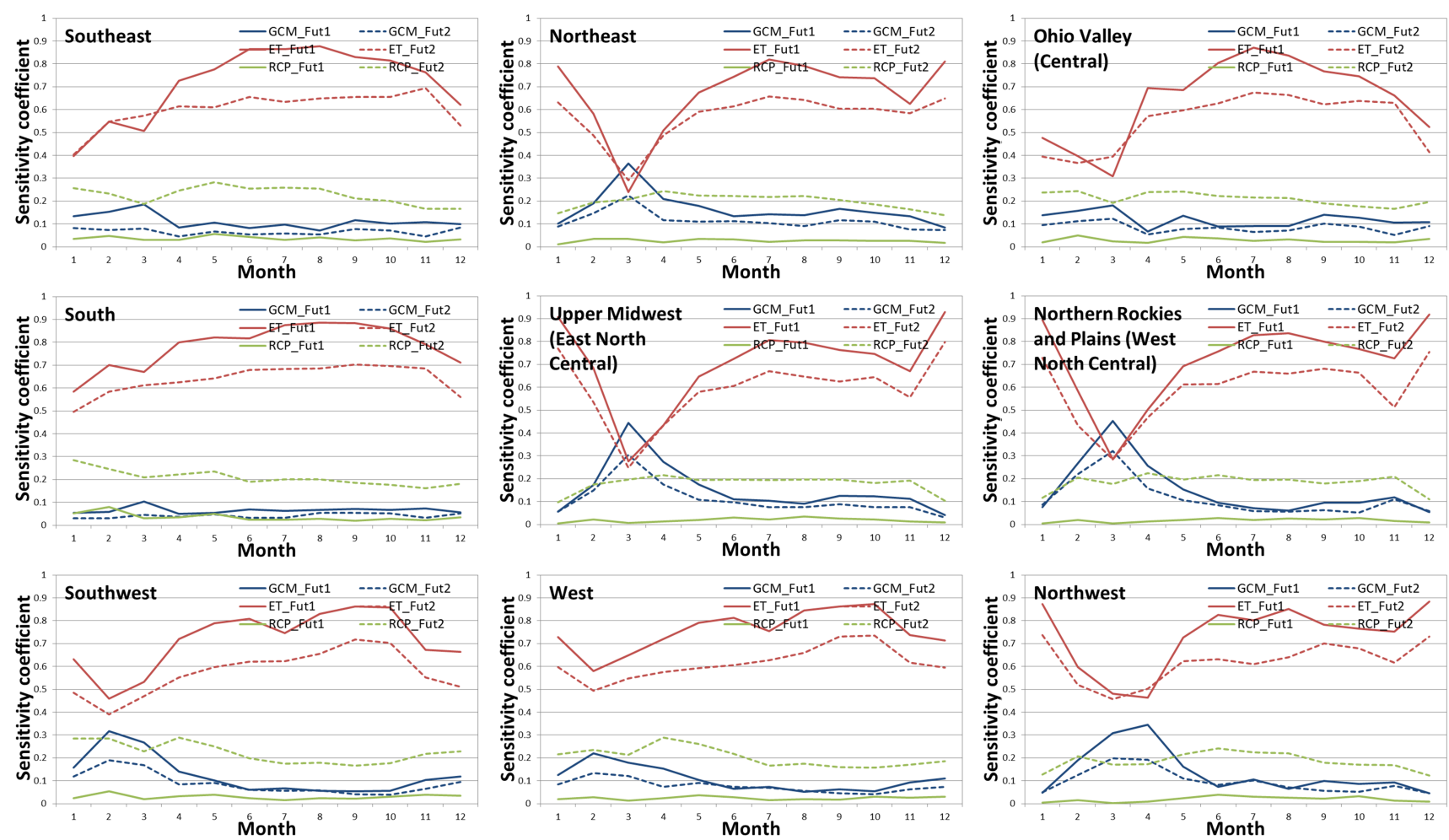

Figure 6. First-order sensitivity analysis results of change in reference evapotranspiration. Solid lines represent future period 1 (2030-2060) and dotted lines represent future period 2 (2070-2100). Blue lines represent the first-order effect of GCMs, red lines represent the first-order effect of $\mathrm{ET}_{0}$ estimation methods, and green lines represent the first-order effect of RCPs.

Hamon, Fig. 8c; and Kharrufa, Fig. 8d) predict drier conditions over the continental US than the other methods. The mass transfer-based methods (e.g., Dalton, Fig. 8g, and Meyer, Fig. 8h) predict generally wetter conditions over most of the continental US compared to other methods. The combination method (Penman-Monteith, Fig. 8i) and the radiation-based methods (Irmak-Rn, Fig 8e; Irmak-Rs, Fig. 8f; and Priestley-Taylor, Fig. 8j) generally fall between the mass transfer-based and temperature-based methods, with the combination methods producing slightly drier conditions. Although most methods predict similar spatial patterns of water deficit over the continental US (generally drier conditions in the West, Southwest, and South, and generally wetter elsewhere), the Hamon method predicts a different pattern of water deficit over the Southwest, South, and Northern Rockies and Plains regions.

\subsection{Monte Carlo filtering}

Monte Carlo filtering (Saltelli et al., 2008) was conducted to further investigate whether projected wetter or drier future conditions (i.e., larger or smaller annual mean water deficit) could be attributed to specific GCMs, $\mathrm{ET}_{0}$ estimation methods, or RCP trajectories. Figure 9 shows the histograms for wet conditions and dry conditions in future period 2 over the
Southeast US by GCMs, the $\mathrm{ET}_{0}$ method, and RCP trajectory for the example month of July. Figure 10 shows similar histograms for the Northern Rockies and Plains, a region with differing behavior from the Southeast US. Table 3 shows the $P$ value results for the $X^{2}$ test for all months in both futures for the Southeast and Northern Rockies and Plains regions. $P$ values greater than 0.05 (bold values) indicate the two histograms are not significantly different from each other. Tables 4-6 show the fraction of time that a particular GCM (Table 4), $\mathrm{ET}_{0}$ method (Table 5), or RCP trajectory (Table 6) projected drier future conditions in each of the nine US climate regions for each month, with fractions higher than 0.5 shaded in grey.

\section{Discussion}

Drier conditions in southern regions (Southeast, South, Southwest, and West) and wetter conditions in northern regions (Northeast, Ohio Valley, Upper Midwest, Northern Rockies and Plains, and Northwest) are consistent (Fig. 4) with those reported by McAfee (2013), who used three $\mathrm{ET}_{0}$ methods (Hamon, Priestley-Taylor, and Penman-Monteith) to estimate global changes in $\mathrm{ET}_{0}$ over the entire globe. As found by Baker and Huang (2014) for both CMIP3 and CMIP5 projections, mean $\mathrm{ET}_{0}$ is projected to be higher in fu- 
Table 3. $P$ values of a Chi-square two-sample test for differences among wet condition vs. dry condition pdfs: Southeast US (SE US) and Northern Rockies and Plains (NRP; West North Central) US (bold values indicate that pdfs are not statistically significantly different at $p=0.05)$.

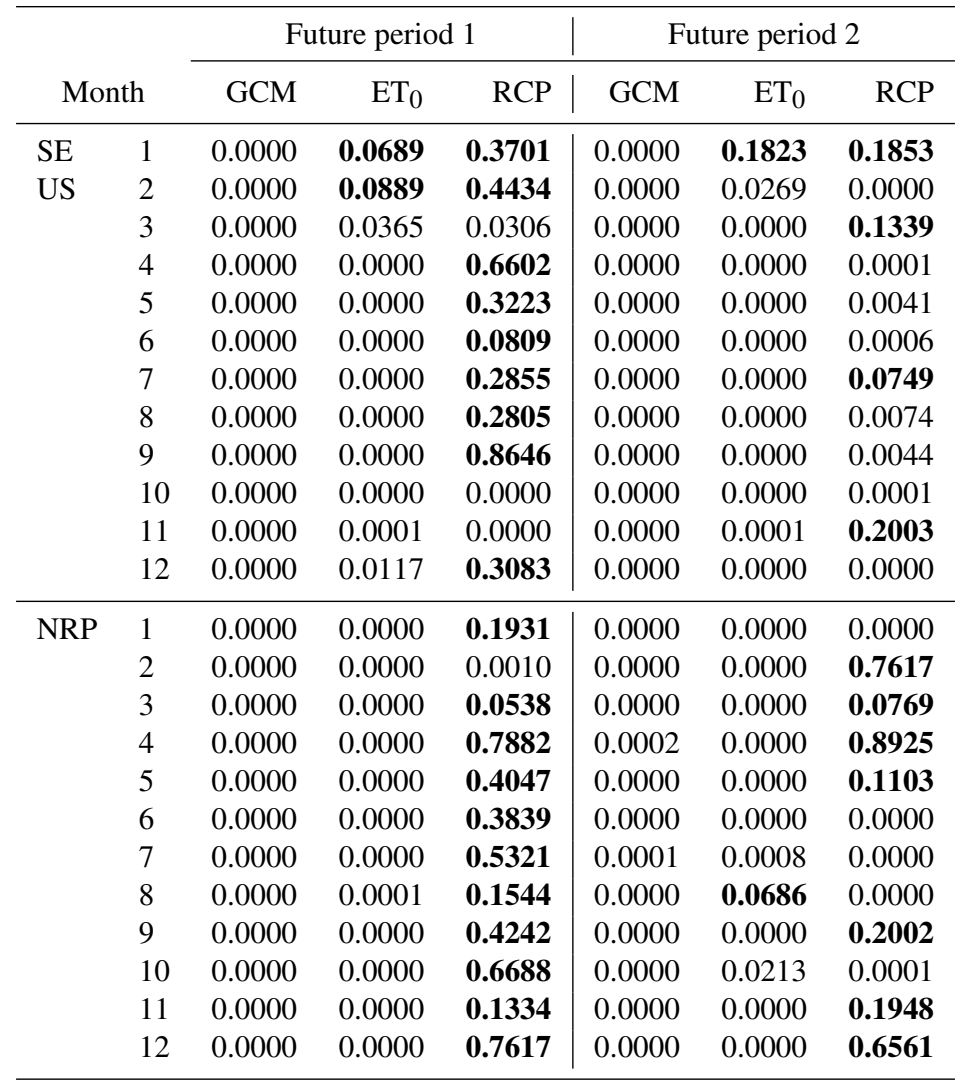

Table 4. The fraction of future dry conditions over all months by GCMs (future periods 1 and 2).

\begin{tabular}{llrlrllllll}
\hline & GCM & SE & South & West & NR & NE & NW & UM & SW & Ohio \\
\hline Future period 1 & BNU-ESM & $\mathbf{0 . 5 7 5}$ & $\mathbf{0 . 5 8 9}$ & $\mathbf{0 . 5 1 1}$ & 0.367 & 0.436 & 0.322 & 0.467 & 0.453 & 0.492 \\
- dry condition & CSIRO-mk3-6-0 & 0.489 & $\mathbf{0 . 6 8 9}$ & $\mathbf{0 . 6 3 9}$ & $\mathbf{0 . 5 4 7}$ & 0.297 & $\mathbf{0 . 5 1 9}$ & 0.381 & $\mathbf{0 . 6 5 3}$ & 0.481 \\
& GFDL-CM3 & 0.414 & $\mathbf{0 . 6 0 8}$ & $\mathbf{0 . 6 8 6}$ & 0.419 & 0.403 & $\mathbf{0 . 5 2 5}$ & 0.383 & $\mathbf{0 . 6 4 7}$ & 0.425 \\
& GFDL-ESM2G & $\mathbf{0 . 7 3 1}$ & $\mathbf{0 . 9 0 0}$ & $\mathbf{0 . 7 5 8}$ & 0.453 & 0.486 & 0.486 & 0.397 & $\mathbf{0 . 8 2 8}$ & $\mathbf{0 . 6 1 7}$ \\
& MIROC-ESM & $\mathbf{0 . 6 3 1}$ & $\mathbf{0 . 5 9 4}$ & $\mathbf{0 . 8 2 2}$ & $\mathbf{0 . 6 2 5}$ & $\mathbf{0 . 6 3 6}$ & $\mathbf{0 . 7 0 8}$ & $\mathbf{0 . 6 8 6}$ & $\mathbf{0 . 6 5 8}$ & $\mathbf{0 . 6 1 1}$ \\
& MPI-ESM-LR & 0.375 & $\mathbf{0 . 7 4 7}$ & $\mathbf{0 . 6 9 4}$ & $\mathbf{0 . 5 4 2}$ & $\mathbf{0 . 5 9 7}$ & $\mathbf{0 . 6 1 1}$ & $\mathbf{0 . 5 5 8}$ & $\mathbf{0 . 7 5 6}$ & $\mathbf{0 . 5 7 5}$ \\
& MRI-CGCM3 & 0.494 & $\mathbf{0 . 5 9 2}$ & $\mathbf{0 . 6 3 9}$ & 0.400 & $\mathbf{0 . 5 4 4}$ & $\mathbf{0 . 5 5 3}$ & 0.350 & $\mathbf{0 . 5 4 7}$ & $\mathbf{0 . 5 0 6}$ \\
& NorESM1-M & 0.492 & $\mathbf{0 . 7 6 4}$ & $\mathbf{0 . 7 7 8}$ & 0.475 & 0.400 & $\mathbf{0 . 6 1 1}$ & 0.475 & $\mathbf{0 . 7 5 3}$ & $\mathbf{0 . 5 0 8}$ \\
& BCC-CSM & $\mathbf{0 . 7 2 8}$ & $\mathbf{0 . 7 3 9}$ & $\mathbf{0 . 8 2 8}$ & $\mathbf{0 . 6 4 2}$ & $\mathbf{0 . 6 0 3}$ & $\mathbf{0 . 6 1 4}$ & $\mathbf{0 . 5 6 4}$ & $\mathbf{0 . 8 2 2}$ & $\mathbf{0 . 6 5 6}$ \\
\hline Future period 2 & BNU-ESM & $\mathbf{0 . 6 0 8}$ & $\mathbf{0 . 7 7 5}$ & $\mathbf{0 . 5 9 7}$ & 0.400 & $\mathbf{0 . 5 2 2}$ & 0.461 & 0.478 & $\mathbf{0 . 5 2 2}$ & $\mathbf{0 . 5 7 2}$ \\
- dry condition & CSIRO-mk3-6-0 & 0.367 & $\mathbf{0 . 6 6 7}$ & $\mathbf{0 . 5 8 3}$ & $\mathbf{0 . 5 2 8}$ & 0.225 & $\mathbf{0 . 5 2 8}$ & 0.433 & $\mathbf{0 . 6 3 3}$ & 0.461 \\
& GFDL-CM3 & 0.467 & $\mathbf{0 . 7 6 7}$ & $\mathbf{0 . 7 8 9}$ & 0.461 & $\mathbf{0 . 5 1 4}$ & $\mathbf{0 . 5 4 2}$ & $\mathbf{0 . 5 0 8}$ & $\mathbf{0 . 7 9 4}$ & 0.469 \\
& GFDL-ESM2G & $\mathbf{0 . 7 2 2}$ & $\mathbf{0 . 8 3 1}$ & $\mathbf{0 . 6 9 4}$ & 0.478 & $\mathbf{0 . 5 1 9}$ & $\mathbf{0 . 5 2 5}$ & 0.397 & $\mathbf{0 . 6 7 2}$ & $\mathbf{0 . 5 8 1}$ \\
& MIROC-ESM & $\mathbf{0 . 6 7 2}$ & $\mathbf{0 . 6 8 6}$ & $\mathbf{0 . 8 9 7}$ & $\mathbf{0 . 7 4 2}$ & $\mathbf{0 . 7 3 1}$ & $\mathbf{0 . 7 2 8}$ & $\mathbf{0 . 7 0 0}$ & $\mathbf{0 . 7 3 9}$ & $\mathbf{0 . 6 6 4}$ \\
& MPI-ESM-LR & 0.442 & $\mathbf{0 . 8 0 0}$ & $\mathbf{0 . 7 7 8}$ & $\mathbf{0 . 5 1 9}$ & $\mathbf{0 . 5 4 2}$ & $\mathbf{0 . 6 3 9}$ & 0.450 & $\mathbf{0 . 8 0 0}$ & 0.450 \\
& MRI-CGCM3 & $\mathbf{0 . 5 0 8}$ & $\mathbf{0 . 7 0 3}$ & $\mathbf{0 . 5 8 1}$ & 0.422 & 0.481 & $\mathbf{0 . 5 2 8}$ & 0.439 & $\mathbf{0 . 5 1 7}$ & $\mathbf{0 . 5 5 6}$ \\
& NorESM1-M & $\mathbf{0 . 5 9 4}$ & $\mathbf{0 . 8 0 8}$ & $\mathbf{0 . 7 2 2}$ & $\mathbf{0 . 5 0 0}$ & 0.461 & $\mathbf{0 . 5 5 0}$ & 0.481 & $\mathbf{0 . 7 3 1}$ & $\mathbf{0 . 5 9 4}$ \\
& BCC-CSM & $\mathbf{0 . 6 2 8}$ & $\mathbf{0 . 6 9 7}$ & $\mathbf{0 . 8 7 5}$ & $\mathbf{0 . 7 0 8}$ & $\mathbf{0 . 5 6 7}$ & $\mathbf{0 . 7 0 8}$ & $\mathbf{0 . 5 5 6}$ & $\mathbf{0 . 8 2 5}$ & $\mathbf{0 . 6 0 3}$ \\
\hline
\end{tabular}



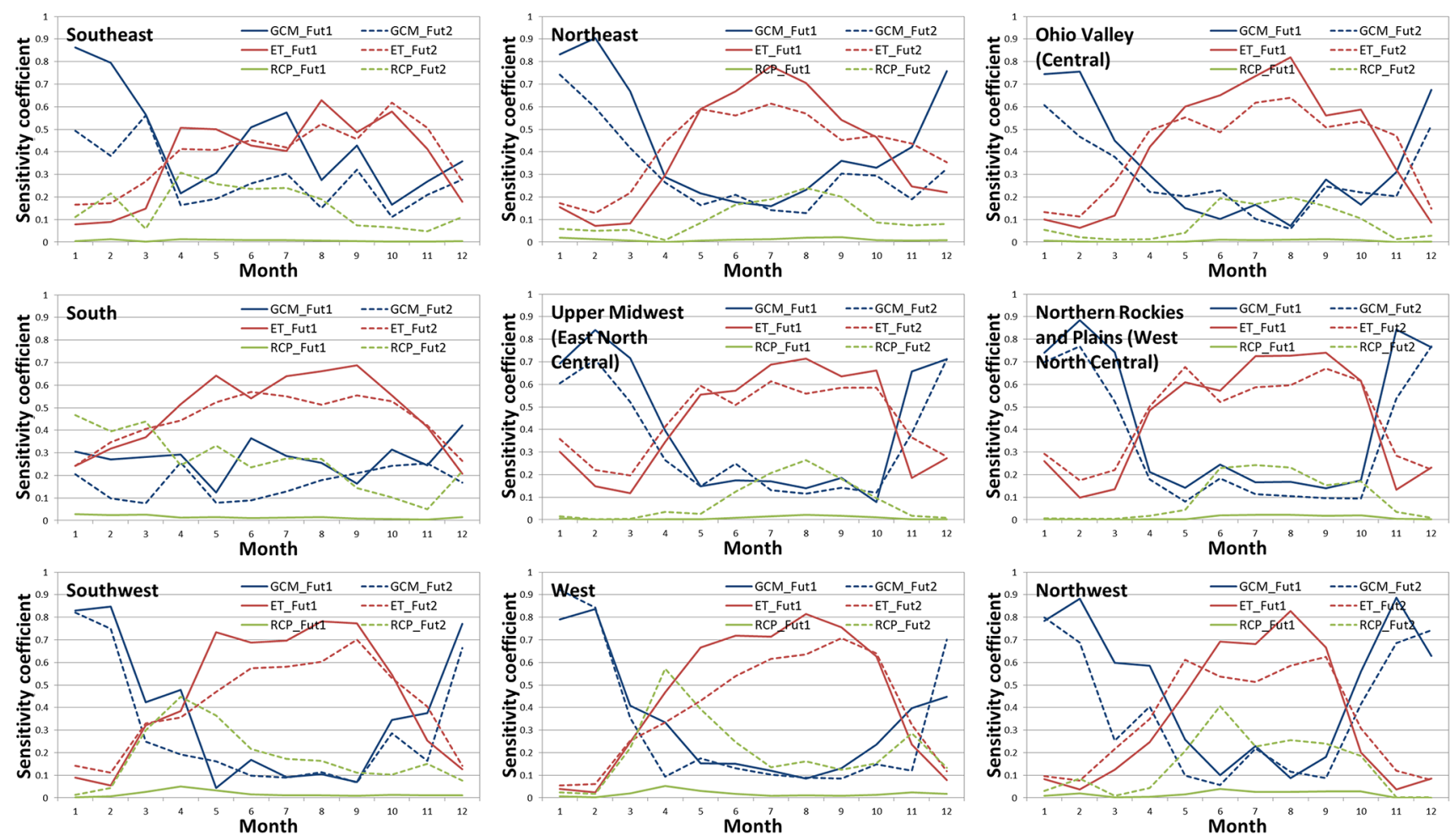

Figure 7. First-order sensitivity analysis results of change in $P-\mathrm{ET}_{0}$. Solid lines represent future period 1 (2030-2060) and dotted lines represent future period 2 (2070-2100). Blue lines represent the first-order effect of GCMs, red lines represent the first-order effect of ET 0 estimation methods, and green lines represent the first-order effect of RCPs.

ture period 2 than in future period 1 , and mean precipitation projections are approximately equivalent in future period 1 and future period 2 . Thus the projected mean changes in water deficit for future period 2 (red lines in Fig. 4) are larger in magnitude than the projected changes for future period 1 (blue lines). In all regions, and for both future periods, the 1 standard deviation error bars bracket zero mean change, indicating large uncertainty in the projections throughout the year.

The choice of GCM is generally more important than the choice of RCP trajectory for projected changes in $P$ (Fig. 5). This is consistent with results found by Gaetani and Mohino (2013) and Knutti and Sedláček (2012), who showed significant differences in precipitation predictions among CMIP5 models. It should be noted that these results do not indicate that the choice of RCP trajectory does not affect the change in precipitation, only that the choice of RCP trajectory is less influential than the choice of GCM. There are no consistent seasonal patterns of the first-order sensitivity coefficients for either GCM or RCP trajectories in either future period. However, during the spring months, the sensitivity of change in $P$ to the choice of RCP trajectory increases substantially in future period 2 compared to future period 1 in the Northeast, Ohio Valley, Upper Midwest, South, Southwest, and West regions.
Higher sensitivity of mean change in $\mathrm{ET}_{0}$ to the choice of $\mathrm{ET}_{0}$ estimation method than the choice of GCM (Fig. 6) is consistent with those found by Kingston et al. (2009), who showed that projected increase in $\mathrm{ET}_{0}$ varied by more than $100 \%$ between $\mathrm{ET}_{0}$ methods, and Schwalm et al. (2013), who found that the choice of $\mathrm{ET}_{0}$ estimation method is sensitive and even more influential than the choice of GCM in predicting $\mathrm{ET}_{0}$. However, neither of these studies looked at the influence of RCP trajectory on $\mathrm{ET}_{0}$ projections, which increases in future period 2 over future period 1, causing a decrease in the sensitivity coefficient of both the GCM and the $\mathrm{ET}_{0}$ method in future period 2. Burke and Brown (2008) evaluated uncertainties in the projection of future drought using several drought indices. They found that there are large uncertainties in regional changes in drought, and changes in drought are dependent on both index definition and GCM ensemble members. Similarly, our results for the projected change in water deficit vary by region and depend strongly on the choice of GCM and $\mathrm{ET}_{0}$ estimation method, but are relatively less sensitive to RCP trajectory (Fig. 7). These findings are similar to results reported by Orlowsky and Seneviratne (2013), who found that the greenhouse gas emission scenario uncertainty is not as important as differences among GCMs or internal climate variability when predicting the Standardized Precipitation Index (SPI) and soil mois- 
The change in annual mean P-ETO of RCP 4.5 trajectory by ETO methods for future period 1
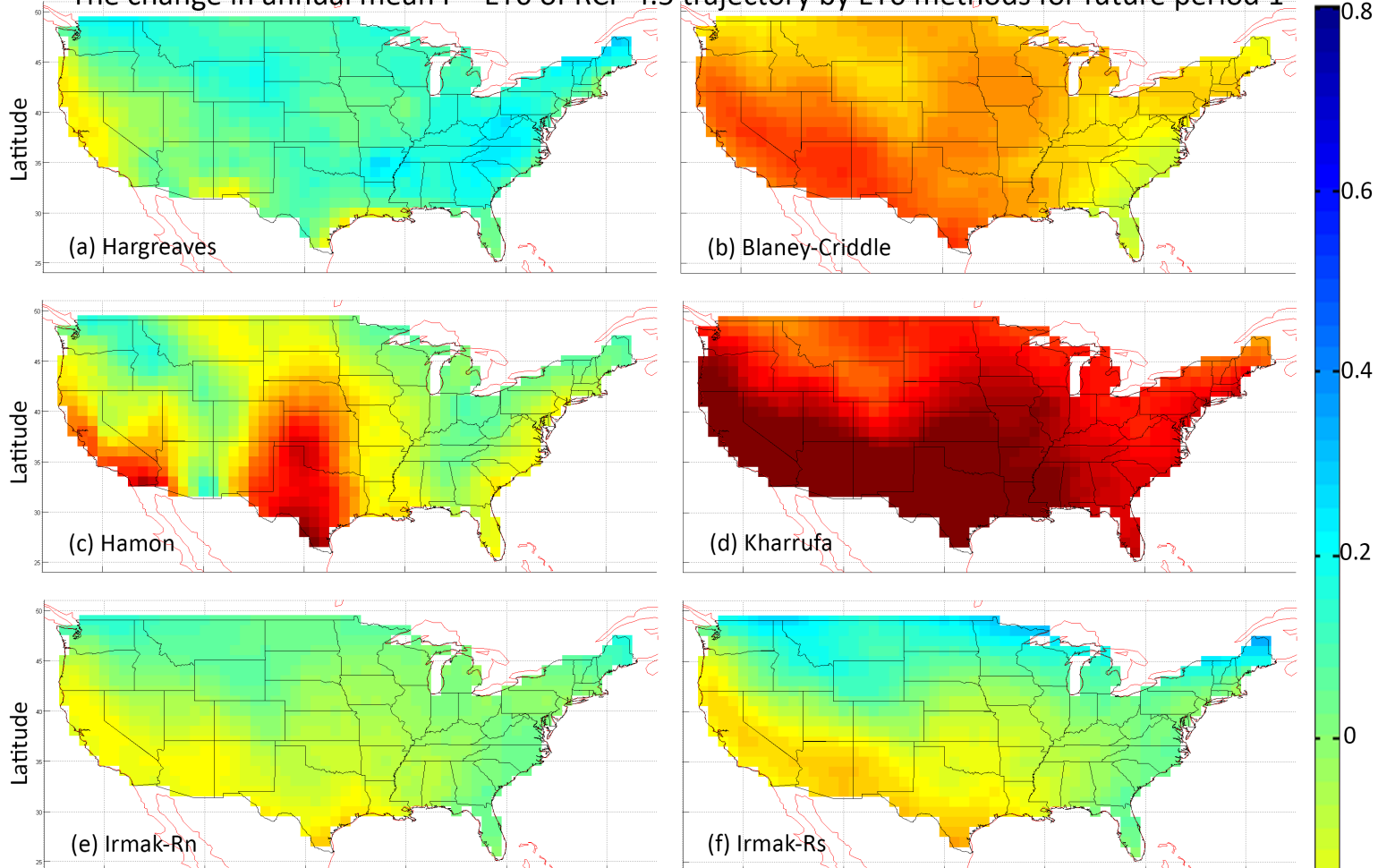

(d) Kharrufa
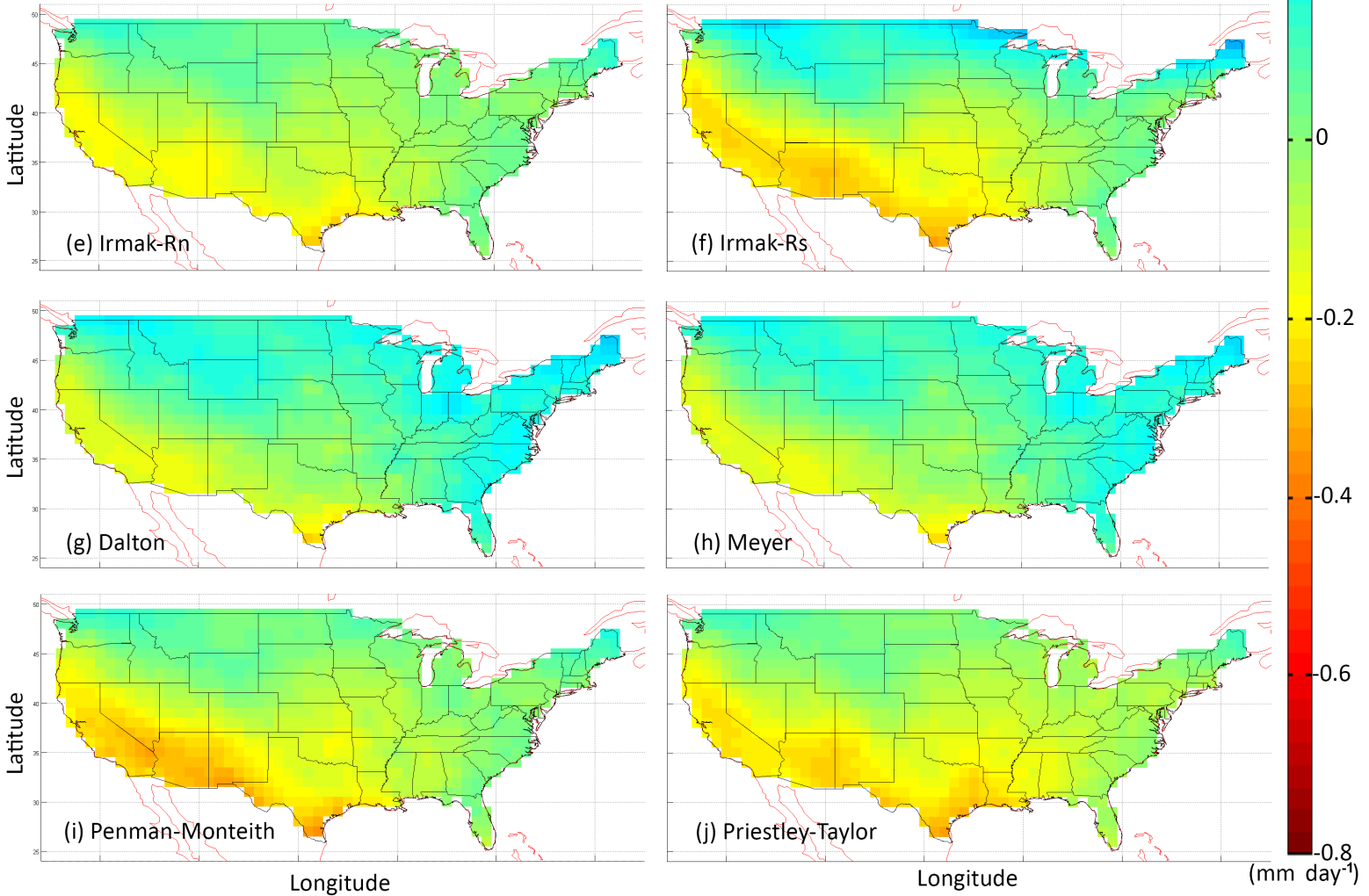

Figure 8. The change in the annual mean $P-\mathrm{ET}_{0}$ of the RCP 4.5 scenario by 10 different evapotranspiration methods. All units are mm day ${ }^{-1}$ and the change is defined as the mean of 2030-2060 minus that of 1950-2005. (All results are interpolated to $1^{\circ} \times 1^{\circ}$ grids and averaged over nine different GCMs.)

ture (SMA). However, they also found that uncertainty due to greenhouse gas emission scenarios increased in later future periods. Taylor et al. (2013) showed the patterns of changes in future drought were similar between the A1B scenario in CMIP3 and the RCP2.6 trajectory in CMIP5, reinforcing our finding that the choice of RCP trajectory is less important than the choice of GCM and $\mathrm{ET}_{0}$ estimation method when estimating future water deficit.
Similar to the results of Kay and Davies (2008) and Bae et al. (2011) the results of our GSA show that the choice of $\mathrm{ET}_{0}$ method has important implications when making future $\mathrm{ET}_{0}$ projections and future water deficit projections (Fig. 8). Kingston et al. (2009) recommended the use of different $\mathrm{ET}_{0}$ equations to evaluate global $\mathrm{ET}_{0}$, and Wang et al. (2015) found that although different methods predict similar future $\mathrm{ET}_{0}$, there are important differences in uncertainties due to 
Table 5. The fraction of future dry conditions over all months by the $\mathrm{ET}_{0}$ estimation method and region (future periods 1 and 2 ).

\begin{tabular}{llrllllllll}
\hline & ET & SE & South & West & NR & NE & NW & UM & SW & Ohio \\
\hline Future period 1 & Hargreaves & 0.302 & 0.426 & $\mathbf{0 . 5 5 9}$ & 0.333 & 0.309 & 0.466 & 0.321 & 0.485 & 0.324 \\
- dry condition & Blaney-Criddle & $\mathbf{0 . 7 3 8}$ & $\mathbf{0 . 8 8 0}$ & $\mathbf{0 . 8 9 8}$ & $\mathbf{0 . 8 4 0}$ & $\mathbf{0 . 7 3 8}$ & $\mathbf{0 . 7 6 2}$ & $\mathbf{0 . 7 8 4}$ & $\mathbf{0 . 9 0 4}$ & $\mathbf{0 . 7 6 9}$ \\
& Hamon & $\mathbf{0 . 6 3 3}$ & $\mathbf{0 . 8 1 8}$ & $\mathbf{0 . 6 6 7}$ & $\mathbf{0 . 5 3 1}$ & 0.494 & 0.497 & 0.457 & $\mathbf{0 . 7 1 3}$ & $\mathbf{0 . 5 4 9}$ \\
& Kharrufa & $\mathbf{0 . 8 8 3}$ & $\mathbf{0 . 9 5 7}$ & $\mathbf{0 . 8 8 9}$ & $\mathbf{0 . 6 3 6}$ & $\mathbf{0 . 6 6 7}$ & $\mathbf{0 . 6 9 8}$ & $\mathbf{0 . 6 3 6}$ & $\mathbf{0 . 8 8 6}$ & $\mathbf{0 . 7 3 8}$ \\
& Irmak-Rn & $\mathbf{0 . 5 2 2}$ & $\mathbf{0 . 6 7 3}$ & $\mathbf{0 . 6 9 4}$ & 0.491 & $\mathbf{0 . 5 1 2}$ & $\mathbf{0 . 5 5 6}$ & 0.494 & $\mathbf{0 . 6 7 9}$ & $\mathbf{0 . 5 8 0}$ \\
& Irmak-Rs & $\mathbf{0 . 5 2 5}$ & $\mathbf{0 . 7 2 2}$ & $\mathbf{0 . 7 3 1}$ & 0.463 & 0.485 & $\mathbf{0 . 5 4 6}$ & 0.460 & $\mathbf{0 . 6 7 9}$ & $\mathbf{0 . 5 5 6}$ \\
& Dalton & 0.364 & $\mathbf{0 . 5 0 3}$ & $\mathbf{0 . 5 8 3}$ & 0.340 & 0.343 & 0.426 & 0.296 & $\mathbf{0 . 5 0 9}$ & 0.380 \\
& Meyer & 0.367 & $\mathbf{0 . 5 3 1}$ & $\mathbf{0 . 5 9 6}$ & 0.346 & 0.324 & 0.435 & 0.290 & $\mathbf{0 . 5 1 2}$ & 0.367 \\
& PM & $\mathbf{0 . 5 3 4}$ & $\mathbf{0 . 6 8 5}$ & $\mathbf{0 . 6 9 4}$ & 0.472 & 0.469 & $\mathbf{0 . 5 2 5}$ & 0.481 & $\mathbf{0 . 6 7 6}$ & $\mathbf{0 . 5 4 0}$ \\
& PT & $\mathbf{0 . 6 0 8}$ & $\mathbf{0 . 7 1 9}$ & $\mathbf{0 . 7 5 0}$ & $\mathbf{0 . 5 1 5}$ & $\mathbf{0 . 5 5 2}$ & $\mathbf{0 . 5 9 0}$ & $\mathbf{0 . 5 1 5}$ & $\mathbf{0 . 7 5 3}$ & $\mathbf{0 . 6 0 8}$ \\
\hline Future period 2 2 dry condition & Hargreaves & 0.352 & $\mathbf{0 . 5 0 6}$ & $\mathbf{0 . 6 0 5}$ & 0.420 & 0.355 & 0.491 & 0.380 & 0.537 & 0.361 \\
& Blaney-Criddle & $\mathbf{0 . 7 6 5}$ & $\mathbf{0 . 9 0 7}$ & $\mathbf{0 . 8 8 0}$ & $\mathbf{0 . 8 7 7}$ & $\mathbf{0 . 7 6 9}$ & $\mathbf{0 . 8 1 8}$ & $\mathbf{0 . 8 3 0}$ & $\mathbf{0 . 9 0 1}$ & $\mathbf{0 . 8 0 6}$ \\
& Hamon & $\mathbf{0 . 6 3 3}$ & $\mathbf{0 . 8 6 1}$ & $\mathbf{0 . 6 7 9}$ & $\mathbf{0 . 5 5 2}$ & 0.491 & $\mathbf{0 . 5 2 8}$ & 0.460 & $\mathbf{0 . 7 1 9}$ & $\mathbf{0 . 5 7 4}$ \\
& Kharrufa & $\mathbf{0 . 8 8 3}$ & $\mathbf{0 . 9 5 4}$ & $\mathbf{0 . 8 9 8}$ & $\mathbf{0 . 7 0 4}$ & $\mathbf{0 . 7 1 3}$ & $\mathbf{0 . 7 2 8}$ & $\mathbf{0 . 6 8 2}$ & $\mathbf{0 . 8 8 3}$ & $\mathbf{0 . 7 8 4}$ \\
& Irmak-Rn & $\mathbf{0 . 5 1 5}$ & $\mathbf{0 . 7 3 8}$ & $\mathbf{0 . 7 1 0}$ & 0.494 & 0.491 & $\mathbf{0 . 5 7 4}$ & $\mathbf{0 . 5 0 3}$ & $\mathbf{0 . 6 8 5}$ & $\mathbf{0 . 5 4 3}$ \\
& Irmak-Rs & $\mathbf{0 . 5 3 4}$ & $\mathbf{0 . 7 9 6}$ & $\mathbf{0 . 7 5 3}$ & 0.485 & 0.497 & $\mathbf{0 . 5 6 2}$ & 0.478 & $\mathbf{0 . 7 1 9}$ & $\mathbf{0 . 5 6 2}$ \\
& Dalton & 0.349 & $\mathbf{0 . 5 9 6}$ & $\mathbf{0 . 6 2 0}$ & 0.389 & 0.358 & 0.475 & 0.315 & $\mathbf{0 . 5 4 0}$ & 0.373 \\
Meyer & 0.352 & $\mathbf{0 . 5 9 6}$ & $\mathbf{0 . 6 3 0}$ & 0.383 & 0.349 & 0.488 & 0.309 & $\mathbf{0 . 5 4 6}$ & 0.361 \\
& PM & $\mathbf{0 . 5 4 3}$ & $\mathbf{0 . 7 4 4}$ & $\mathbf{0 . 7 0 1}$ & 0.475 & 0.485 & $\mathbf{0 . 5 3 1}$ & 0.463 & $\mathbf{0 . 6 7 9}$ & $\mathbf{0 . 5 2 8}$ \\
& PT & $\mathbf{0 . 6 3 9}$ & $\mathbf{0 . 7 8 4}$ & $\mathbf{0 . 7 6 5}$ & $\mathbf{0 . 5 0 9}$ & $\mathbf{0 . 5 6 2}$ & $\mathbf{0 . 5 9 3}$ & $\mathbf{0 . 5 1 5}$ & $\mathbf{0 . 7 1 6}$ & $\mathbf{0 . 6 0 8}$ \\
\hline
\end{tabular}

Table 6. The fraction of future dry conditions over all months by RCP trajectory and region (future periods 1 and 2).

\begin{tabular}{lrrrrrrrrrr}
\hline & RCP & SE & South & West & NR & NE & NW & UM & SW & Ohio \\
\hline Future period 1 & 2.6 & $\mathbf{0 . 5 5 1}$ & $\mathbf{0 . 6 5 7}$ & $\mathbf{0 . 6 6 5}$ & $\mathbf{0 . 5 0 7}$ & $\mathbf{0 . 5 0 2}$ & $\mathbf{0 . 5 4 3}$ & 0.495 & $\mathbf{0 . 6 4 4}$ & $\mathbf{0 . 5 5 3}$ \\
- dry condition & 4.5 & $\mathbf{0 . 5 5 3}$ & $\mathbf{0 . 6 9 8}$ & $\mathbf{0 . 7 3 9}$ & $\mathbf{0 . 5 1 5}$ & 0.475 & $\mathbf{0 . 5 5 4}$ & 0.482 & $\mathbf{0 . 7 3 1}$ & $\mathbf{0 . 5 5 6}$ \\
& 8.5 & $\mathbf{0 . 5 3 9}$ & $\mathbf{0 . 7 1 9}$ & $\mathbf{0 . 7 1 5}$ & 0.468 & 0.491 & $\mathbf{0 . 5 5 4}$ & 0.443 & $\mathbf{0 . 6 6 5}$ & $\mathbf{0 . 5 1 5}$ \\
\hline Future period 2 & 2.6 & $\mathbf{0 . 5 1 6}$ & $\mathbf{0 . 6 4 9}$ & $\mathbf{0 . 6 5 7}$ & 0.486 & $\mathbf{0 . 5 2 4}$ & $\mathbf{0 . 5 1 5}$ & 0.465 & $\mathbf{0 . 6 1 7}$ & $\mathbf{0 . 5 4 5}$ \\
- dry condition & 4.5 & 0.490 & $\mathbf{0 . 7 3 1}$ & $\mathbf{0 . 7 1 2}$ & $\mathbf{0 . 5 1 0}$ & 0.476 & $\mathbf{0 . 5 8 4}$ & 0.494 & $\mathbf{0 . 6 5 8}$ & $\mathbf{0 . 5 2 8}$ \\
& 8.5 & $\mathbf{0 . 6 6 4}$ & $\mathbf{0 . 8 6 4}$ & $\mathbf{0 . 8 0 3}$ & $\mathbf{0 . 5 9 0}$ & $\mathbf{0 . 5 2 0}$ & $\mathbf{0 . 6 3 7}$ & $\mathbf{0 . 5 2 1}$ & $\mathbf{0 . 8 0 3}$ & $\mathbf{0 . 5 7 7}$ \\
\hline
\end{tabular}

$\mathrm{ET}_{0}$ estimation methods and input data reliability. Currently many hydrological models use a single evapotranspiration method for simulation, which may substantially increase the uncertainty and reduce the reliability of future projections. Our results strongly indicate that an ensemble of $\mathrm{ET}_{0}$ estimation methods should be used to understand potential future water availability and water deficit due to climate change.

Monte Carlo filtering results (Fig. 9 and 10, Table 3) indicate that GCMs and $\mathrm{ET}_{0}$ methods both produce statistically significant different wet condition and dry condition histograms in both the Southeast and Northern Rockies and Plains regions for almost all months in both future periods. This indicates that particular GCMs and $\mathrm{ET}_{0}$ methods tend to systematically produce wet or dry conditions. Some GCMs (i.e., MIROC-ESM and BCC-CSM; Table 4) and $\mathrm{ET}_{0}$ methods (i.e., Priestley-Taylor, Blaney-Criddle, and Kharrufa; Table 5) predict dry conditions the majority of the time for all regions in both future periods. However, the remaining GCMs and $\mathrm{ET}_{0}$ methods project both wetter and drier fu- tures, depending on the region and future period. Results in Tables 4 through 6 show that for the South, West, and Southwest regions, drier conditions are predicted the majority of the time in both future periods by all GCMs and RCP trajectories, and by all $\mathrm{ET}_{0}$ methods except Hargreaves. For RCP trajectory, $P$ values indicate that the histograms are statistically significantly different in fewer cases than for either GCMs or $\mathrm{ET}_{0}$ methods for both future periods 1 and 2 (Table 3). These results are consistent with the first-order sensitivity coefficient results that showed the RCP trajectory is not as important a factor as GCMs or $\mathrm{ET}_{0}$ methods in driving differences in future projections, but that the sensitivity to choice of RCP trajectory increases in future period 2.

GCMs estimate some climate variables, such as temperature, with higher confidence than other variables (Randall et al., 2007). However, for some evapotranspiration estimation methods the effect of temperature on evaporation is smaller than other climate variables (Linacre, 1994; Roderick et al., 2009a, b; Thom et al., 1981). We found that temperature and 

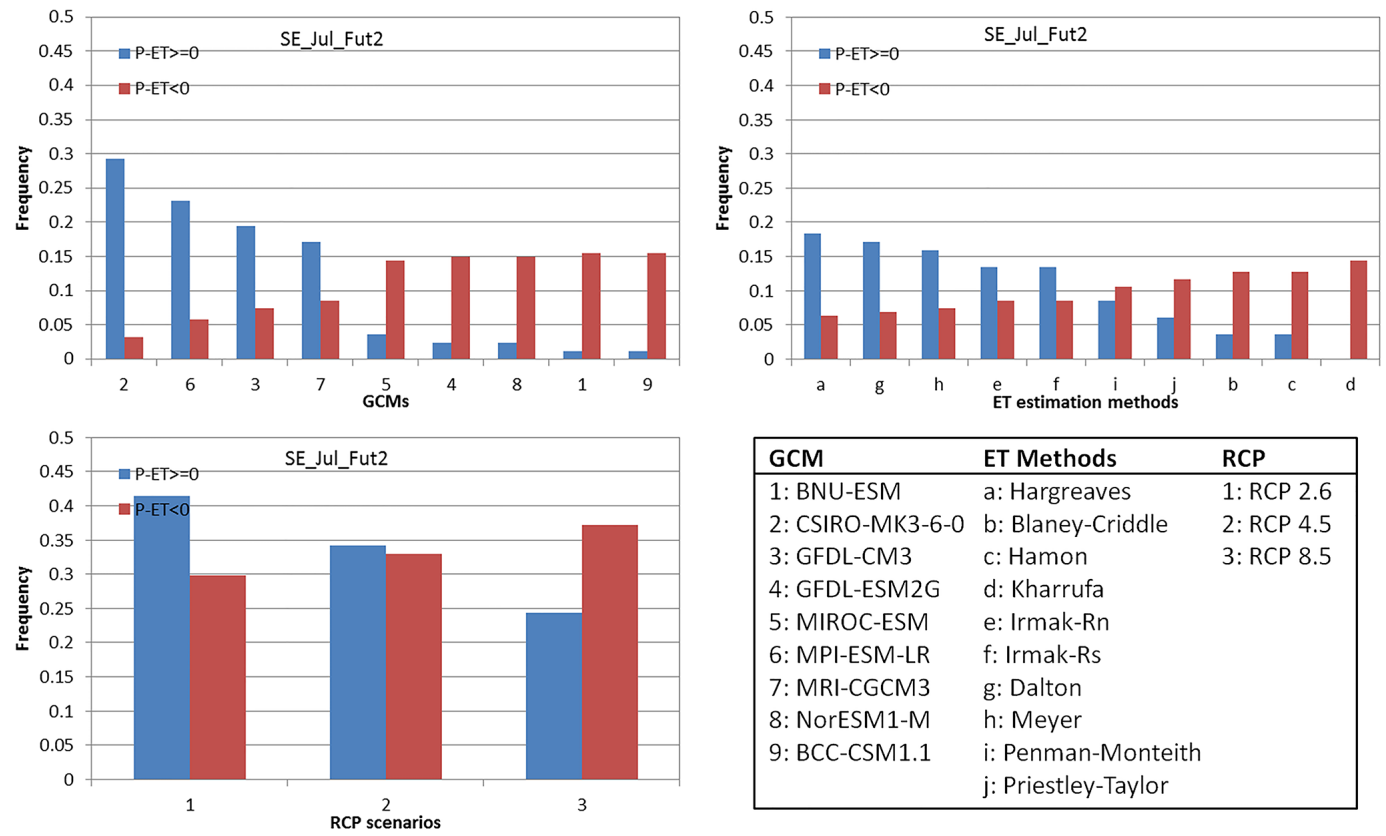

\begin{tabular}{|lll|}
\hline GCM & ET Methods & RCP \\
\hline 1: BNU-ESM & a: Hargreaves & 1: RCP 2.6 \\
2: CSIRO-MK3-6-0 & b: Blaney-Criddle & 2: RCP 4.5 \\
3: GFDL-CM3 & c: Hamon & 3: RCP 8.5 \\
4: GFDL-ESM2G & d: Kharrufa & \\
5: MIROC-ESM & e: Irmak-Rn & \\
6: MPI-ESM-LR & f: Irmak-Rs & \\
7: MRI-CGCM3 & g: Dalton & \\
8: NorESM1-M & h: Meyer \\
9: BCC-CSM1.1 & i: Penman-Monteith \\
& j: Priestley-Taylor \\
\hline
\end{tabular}

Figure 9. Histograms for projected future period 2 wet conditions and dry conditions in the Southeast US by GCMs, the ET 0 method, and RCP trajectory for the month of July.
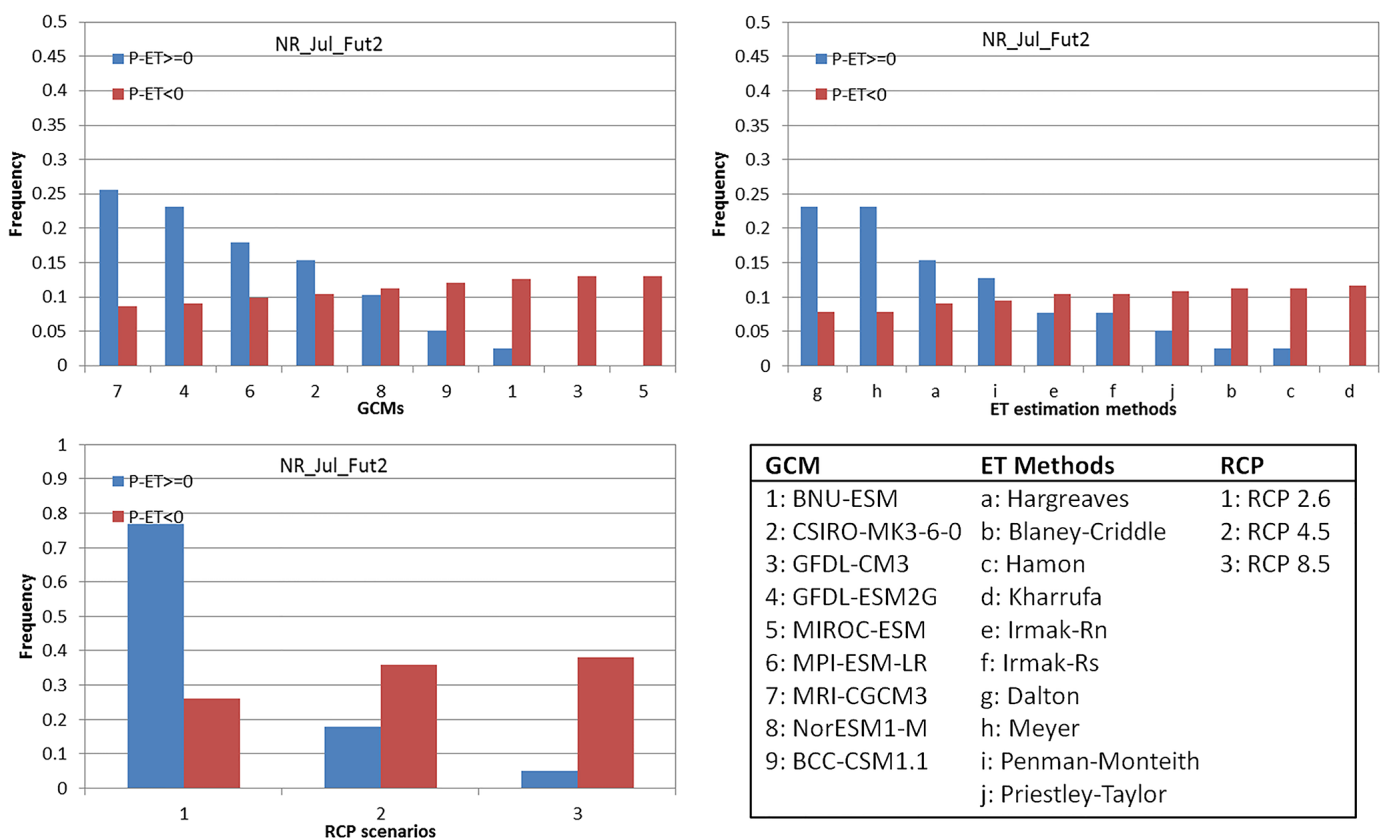

\begin{tabular}{|lll|}
\hline GCM & ET Methods & RCP \\
\hline 1: BNU-ESM & a: Hargreaves & 1: RCP 2.6 \\
2: CSIRO-MK3-6-0 & b: Blaney-Criddle & 2: RCP 4.5 \\
3: GFDL-CM3 & c: Hamon & 3: RCP 8.5 \\
4: GFDL-ESM2G & d: Kharrufa & \\
5: MIROC-ESM & e: Irmak-Rn & \\
6: MPI-ESM-LR & f: Irmak-Rs & \\
7: MRI-CGCM3 & g: Dalton & \\
8: NorESM1-M & h: Meyer \\
9: BCC-CSM1.1 & i: Penman-Monteith \\
& j: Priestley-Taylor \\
\hline
\end{tabular}

Figure 10. Histograms for projected future period 2 wet conditions and dry conditions in the Northern Rockies and Plains US by GCMs, the $\mathrm{ET}_{0}$ method, and RCP trajectory for the month of July.

net radiation from the CMIP5 GCMs show increasing trends over the 2005-2100 time period, while wind speed and surface pressure are relatively constant (Fig. S3). Because we considered various $\mathrm{ET}_{0}$ estimation methods our results include the impacts of the different physics represented in the $\mathrm{ET}_{0}$ methods, the projected changes in each of the climate variables contributing to the different $\mathrm{ET}_{0}$ methods, and the reliability of the predictions of each variable. 


\section{Summary and conclusions}

Future changes in precipitation and evapotranspiration will lead to changes in the hydrologic balance. This study clearly shows that the uncertainty caused by different GCMs, $\mathrm{ET}_{0}$ methods, and RCP trajectories makes actionable water resources planning based on climate change projections difficult. Understanding and quantifying how these projected changes vary with choice of GCM, $\mathrm{ET}_{0}$ method, and RCP trajectory is important for designing robust ensembles of scenarios to include in future water resources planning. This study assessed the future mean change in monthly precipitation, evapotranspiration, and water deficit $\left(P-\mathrm{ET}_{0}\right)$ projected by CMIP5 simulations over the continental US and analyzed the sensitivity of the projected changes to the choice of GCM, $\mathrm{ET}_{0}$ estimation method, and RCP trajectory. Nine GCMs, $10 \mathrm{ET}_{0}$ estimation methods, and $3 \mathrm{RCP}$ trajectories were included in the analyses. Variance-based global sensitivity analysis (Saltelli et al., 2010) was conducted in order to determine the relative contributions of the choice of GCMs, $\mathrm{ET}_{0}$ estimation methods, and RCP trajectory to uncertainty in future prediction. Monte Carlo filtering was used to investigate whether particular GCMs, $\mathrm{ET}_{0}$ methods, and/or RCP scenarios consistently led to wet or dry future projections.

The global sensitivity analyses showed that projected changes in precipitation are more sensitive to the choice of GCM than the choice of RCP trajectory over the entire continental US for both future periods. However, the choice of RCP trajectory becomes more important in future period 2 . The most sensitive factor for the future $\mathrm{ET}_{0}$ projections is the choice of $\mathrm{ET}_{0}$ estimation method for all regions in both future periods. The first-order sensitivity of projected change in future $\mathrm{ET}_{0}$ to the choice of RCP trajectory increases in future period 2 compared to future period 1 , with a concomitant decrease in the first-order sensitivity to the choice of GCM. For projected change in future water deficit, the choice of $\mathrm{ET}_{0}$ method constitutes the dominant source of uncertainty in warmer months (May through September), and the choice of GCM is the dominant source of uncertainty in the cooler months (November through March) over all regions except the Southeast, where the sensitivity of GCM and $\mathrm{ET}_{0}$ method are roughly equal throughout the year. Sensitivity of change in future water deficit to RCP trajectory is very small for future period 1 , but increased in future period 2 .

Monte Carlo filtering results indicated that both GCMs and $\mathrm{ET}_{0}$ methods produced statistically different histograms for wetter or drier future conditions (i.e., larger or smaller mean future water deficit) for almost all months in both future periods. Two GCMs (MIROC-ESM and BCC-CSM) and three $\mathrm{ET}_{0}$ methods (Priestley-Taylor, Blaney-Criddle, and Kharrufa) predicted dry conditions the majority of the time for all regions in both future periods; however, the remaining GCMs and $\mathrm{ET}_{0}$ methods projected both wetter and drier futures, depending on the region.
Results of this study indicate that when predicting the effects of future climate on water resources, the choice of evapotranspiration method should be carefully evaluated. Rather than the typical practice of using a single $\mathrm{ET}_{0}$ method to drive a hydrologic model with future climate projections, an ensemble of $\mathrm{ET}_{0}$ methods should be used in addition to an ensemble of GCMs and a variety of RCP trajectories. The GSA methodology adopted here assumed that all the GCMs, $\mathrm{ET}_{0}$ methods, and RCP trajectories used in this study were equally appropriate for use in all US regions (i.e., the sensitivity coefficients were evaluated by equally weighting each $\mathrm{GCM}, \mathrm{ET}_{0}$ method, and RCP trajectory), which is likely not to be the case. When making future projections of potential climate change in water resources, reliability ensemble averaging (REA; Giorgi and Mearns, 2002) or Bayesian-based indicator-weighting (Asefa and Adams, 2013; Tebaldi et al., 2005; Xing et al., 2014) could be used to weight the results of an ensemble of GCMs and ET methods based on how close the retrospective $\mathrm{GCM}-\mathrm{ET}_{0}$ method predictions agree with past observations (bias criterion) and how well the future GCM-ET $T_{0}-\mathrm{RCP}$ projections agree with other future GCM$\mathrm{ET}_{0}-\mathrm{RCP}$ predictions (convergence criterion).

This study assumed that $\mathrm{ET}_{0}$ methods that have been developed and parameterized based on vegetation response to current $\mathrm{CO}_{2}$ levels and climatic conditions will be valid under future $\mathrm{CO}_{2}$ levels and climatic conditions. Future research should explore the validity of this assumption by incorporating potential changes in plant transpiration (e.g., stomatal conductance) to changing $\mathrm{CO}_{2}$ levels into the $\mathrm{ET}_{0}$ estimation methodologies.

\section{Data availability}

The underlying data of this research can be downloaded from the Program For Climate Model Diagnosis and Intercomparison (PCMDI, http://pcmdi-cmip.llnl.gov/cmip5/index.html) and the North American Land Data Assimilation System (NLDAS-2, http://ldas.gsfc.nasa.gov/nldas/NLDAS2forcing. php).

\section{The Supplement related to this article is available online at doi:10.5194/hess-20-3245-2016-supplement.}

Acknowledgements. This research was supported by Tampa Bay Water and the University of Florida Water Institute. We acknowledge the modeling groups participating in the Program for Climate Model Diagnosis and Inter-comparison (PCMDI) for their role in making the CMIP5 (Coupled Model Intercomparison Project) multi-model data set available.

Edited by: W. Buytaert

Reviewed by: two anonymous referees 


\section{References}

Allen, R. G., Pereira, L. S., Raes, D., and Smith, M.: Crop evapotranspiration: guidelines for computing crop water requirements, FAO Irrigation and Drainage Paper 56, 1998.

Asefa, T. and Adams, A.: Reducing bias-corrected precipitation projection uncertainties: a Bayesian-based indicatorweighting approach, Reg. Environ. Change, 13, 111-120, doi:10.1007/s10113-013-0431-9, 2013.

Bae, D. H., Jung, I. W., and Lettenmaier, D. P.: Hydrologic uncertainties in climate change from IPCC AR4 GCM simulations of the Chungju Basin, Korea, J. Hydrol., 401, 90-105, doi:10.1016/j.jhydrol.2011.02.012, 2011.

Baker, N. C. and Huang, H.-P.: A Comparative Study of Precipitation and Evaporation between CMIP3 and CMIP5 Climate Model Ensembles in Semiarid Regions, J. Climate, 27, 37313749, doi:10.1175/JCLI-D-13-00398.1, 2014.

Bentsen, M., Bethke, I., Debernard, J. B., Iversen, T., Kirkevåg, A., Seland, Ø., Drange, H., Roelandt, C., Seierstad, I. A., Hoose, C., and Kristjánsson, J. E.: The Norwegian Earth System Model, NorESM1-M - Part 1: Description and basic evaluation of the physical climate, Geosci. Model Dev., 6, 687-720, doi:10.5194/gmd-6-687-2013, 2013.

Block, K. and Mauritsen, T.: Forcing and feedback in the MPIESM-LR coupled model under abruptly quadrupled $\mathrm{CO}_{2}$, J. Adv. Model. Earth Syst., 5, 676-691, doi:10.1002/jame.20041, 2013.

Burke, E. J. and Brown, S. J.: Evaluating Uncertainties in the Projection of Future Drought, J. Hydrometeorol., 9, 292-299, doi:10.1175/2007JHM929.1, 2008.

Chaouche, K., Neppel, L., Dieulin, C., Pujol, N., Ladouche, B., Martin, E., Salas, D., and Caballero, Y.: Analyses of precipitation, temperature and evapotranspiration in a French Mediterranean region in the context of climate change, Compt Rendus Geosci., 342, 234-243, doi:10.1016/j.crte.2010.02.001, 2010.

Chong-Hai, X. and Ying, X.: The projection of temperature and precipitation over China under RCP scenarios using a CMIP5 multi-model ensemble, Atmos. Ocean. Sci. Lett., 5, 527-533, doi:10.1080/16742834.2012.11447042, 2012.

Gaetani, M. and Mohino, E.: Decadal prediction of the sahelian precipitation in CMIP5 simulations, J. Climate, 26, 7708-7719, doi:10.1175/JCLI-D-12-00635.1, 2013.

Georgakakos, A., Fleming, P., Dettinger, M., Peters-Lidard, C., Richmond, T., Reckhow, K., White, K., and Yates, D.: Ch. 3: Water Resources. Climate Change Impacts in the United States: The Third National Climate Assessment, 2014.

Giorgi, F. and Mearns, L.: Calculation of average, uncertainty range, and reliability of regional climate changes from AOGCM simulations via the "reliability ensemble averaging"(REA) method, J. Climate, 15, 1141-1158, 2002.

Guo, H., Golaz, J.-C., Donner, L. J., Ginoux, P., and Hemler, R. S.: Multivariate Probability Density Functions with Dynamics in the GFDL Atmospheric General Circulation Model: Global Tests, J. Climate, 27, 2087-2108, doi:10.1175/JCLI-D-13-00347.1, 2014.

Hargreaves, G. H. and Allen, R. G.: History and Evaluation of Hargreaves Evapotranspiration Equation, J. Irrig. Drain. Eng., 129, 53-63, doi:10.1061/(ASCE)0733-9437(2003)129:1(53), 2003.

Hawkins, E. and Sutton, R.: The potential to narrow uncertainty in regional climate predictions, B. Am. Meteorol. Soc., 90, 10951107, doi:10.1175/2009BAMS2607.1, 2009
Hawkins, E. and Sutton, R.: The potential to narrow uncertainty in projections of regional precipitation change, Clim. Dynam., 37, 407-418, doi:10.1007/s00382-010-0810-6, 2010.

Homma, T. and Saltelli, A.: Importance measures in global sensitivity analysis of nonlinear models, Reliab. Eng. Syst. Saf., 52, 1-17, doi:10.1016/0951-8320(96)00002-6, 1996.

Hwang, S. and Graham, W. D.: Development and comparative evaluation of a stochastic analog method to downscale daily GCM precipitation, Hydrol. Earth Syst. Sci., 17, 4481-4502, doi:10.5194/hess-17-4481-2013, 2013.

Irmak, S., Irmak, A., Allen, R. G., and Jones, J. W.: Solar and Net Radiation-Based Equations to Estimate Reference Evapotranspiration in Humid Climates, J. Irrig. Drain. Eng., 129, 336-347, doi:10.1061/(ASCE)0733-9437(2003)129:5(336), 2003.

Ishak, A. M., Bray, M., Remesan, R., and Han, D.: Estimating reference evapotranspiration using numerical weather modelling, Hydrol. Process., 24, 3490-3509, doi:10.1002/hyp.7770, 2010.

Ji, D., Wang, L., Feng, J., Wu, Q., Cheng, H., Zhang, Q., Yang, J., Dong, W., Dai, Y., Gong, D., Zhang, R.-H., Wang, X., Liu, J., Moore, J. C., Chen, D., and Zhou, M.: Description and basic evaluation of Beijing Normal University Earth System Model (BNU-ESM) version 1, Geosci. Model Dev., 7, 2039-2064, doi:10.5194/gmd-7-2039-2014, 2014.

Johnson, F. and Sharma, A.: Measurement of GCM Skill in Predicting Variables Relevant for Hydroclimatological Assessments, J Climate, 22, 4373-4382, doi:10.1175/2009JCLI2681.1, 2009.

Karl, T. R. and Koss, W. J.: Historical Climatology Series 4-3: Regional and National Monthly, Seasonal, and Annual Temperature Weighted by Area, 1895-1983, 1984.

Kay, A. L. and Davies, H. N.: Calculating potential evaporation from climate model data: A source of uncertainty for hydrological climate change impacts, J. Hydrol., 358, 221-239, doi:10.1016/j.jhydrol.2008.06.005, 2008.

Kharin, V. V., Zwiers, F. W., Zhang, X., and Wehner, M.: Changes in temperature and precipitation extremes in the CMIP5 ensemble, Climate Change, 119, 345-357, doi:10.1007/s10584-013-07058, 2013.

Kingston, D. G., Todd, M. C., Taylor, R. G., Thompson, J. R., and Arnell, N. W.: Uncertainty in the estimation of potential evapotranspiration under climate change, Geophys. Res. Lett., 36, L20403, doi:10.1029/2009GL040267, 2009.

Knutti, R. and Sedláček, J.: Robustness and uncertainties in the new CMIP5 climate model projections, Nature Climate Change, 3, 369-373, doi:10.1038/nclimate1716, 2012.

Koedyk, L. P. and Kingston, D. G.: Potential evapotranspiration method influence on climate change impacts on river flow: a mid-latitude case study, Hydrol. Res., doi:10.2166/nh.2016.152, 2016.

LaFond, K. M., Griffis, V. W., and Spellman, P.: Forcing Hydrologic Models with GCM Output: Bias Correction vs. the "Delta Change" Method, in World Environmental and Water Resources Congress 2014, 1, 2146-2155, American Society of Civil Engineers, Reston, VA., 2014.

Linacre, E. T.: Estimating US Class A Pan Evaporation from Few Climate Data, Water Int., 19, 5-14, doi:10.1080/02508069408686189, 1994.

Maurer, E. P. and Hidalgo, H. G.: Utility of daily vs. monthly large-scale climate data: an intercomparison of two statistical 
downscaling methods, Hydrol. Earth Syst. Sci., 12, 551-563, doi:10.5194/hess-12-551-2008, 2008.

McAfee, S. A.: Methodological differences in projected potential evapotranspiration, Climate Change, 120, 915-930, doi:10.1007/s10584-013-0864-7, 2013.

Melillo, J. M., Richmond, T., and Yohe, G. W.: Climate change impacts in the United States: The Third National Climate Assessment, US Global Change Research Program, 841, doi:10.7930/J0Z31WJ2, 2014.

Mood, A. M., Graybill, F. A., and Boes, D. C.: Introduction to theory of statistics, McGraw-Hill, Inc., 1974.

Muerth, M. J., Gauvin St-Denis, B., Ricard, S., Velázquez, J. A., Schmid, J., Minville, M., Caya, D., Chaumont, D., Ludwig, R., and Turcotte, R.: On the need for bias correction in regional climate scenarios to assess climate change impacts on river runoff, Hydrol. Earth Syst. Sci., 17, 1189-1204, doi:10.5194/hess-171189-2013, 2013.

Orlowsky, B. and Seneviratne, S. I.: Elusive drought: uncertainty in observed trends and short- and long-term CMIP5 projections, Hydrol. Earth Syst. Sci., 17, 1765-1781, doi:10.5194/hess-171765-2013, 2013.

Quintana Seguí, P., Ribes, A., Martin, E., Habets, F., and Boé, J.: Comparison of three downscaling methods in simulating the impact of climate change on the hydrology of Mediterranean basins, J. Hydrol., 383, 111-124, doi:10.1016/j.jhydrol.2009.09.050, 2010.

Pierce, D. W., Cayan, D. R., Maurer, E. P., Abatzoglou, J. T., and Hegewisch, K. C.: Improved bias correction techniques for hydrological simulations of climate change, J. Hydrometeorol., 150915153707007, doi:10.1175/JHM-D-14-0236.1, 2015.

Randall, D. A., Wood, R. A., Bony, S., Colman, R., Fichefet, T., Fyve, J., Kattsov, V., Pitman, A., Shukla, J., Srinivasan, J., Stouffer, R. J., Sumi, A., and Taylor, K. E.: Climate Models and Their Evaluation, in Climate Change 2007: The Physical Science Basis, Contribution of Working Group I to the Fourth Assessment Report of the Intergovernmental Panel on Climate Change, edited by: Solomon, S., Qin, D., Manning, M., Chen, Z., Marquis, M., Averyt, K. B., Tignor, M., and Miller, H. L., Cambridge University Press, Cambridge, United Kingdom and New York, NY, USA, 591-662, 2007.

Rao, J. N. K. and Scott, A. J.: The Analysis of Categorical Data From Complex Sample Survey?: Chi-Squared Tests for Goodness of Fit and Independence in Two-Way Tables, J. Am. Stat. Assoc., 76, 221-230, 1981.

Roderick, M. L., Hobbins, M. T., and Farquhar, G. D.: Pan Evaporation Trends and the Terrestrial Water Balance. I. Principles and Observations, Geogr. Compass, 3, 746-760, doi:10.1111/j.17498198.2008.00213.x, 2009a.

Roderick, M. L., Hobbins, M. T., and Farquhar, G. D.: Pan Evaporation Trends and the Terrestrial Water Balance. II. Energy Balance and Interpretation, Geogr. Compass, 3, 761-780, doi:10.1111/j.1749-8198.2008.00214.x, 2009b.

Rose, K. A., Smith, E. P., Gardner, R. H., Brenkert, A. L., and Bartell, S. M.: Parameter sensitivities, monte carlo filtering, and model forecasting under uncertainty, J. Forecast., 10, 117-133, doi:10.1002/for.3980100108, 1991.

Rotstayn, L. D., Jeffrey, S. J., Collier, M. A., Dravitzki, S. M., Hirst, A. C., Syktus, J. I., and Wong, K. K.: Aerosol- and greenhouse gas-induced changes in summer rainfall and circulation in the
Australasian region: a study using single-forcing climate simulations, Atmos. Chem. Phys., 12, 6377-6404, doi:10.5194/acp-126377-2012, 2012.

Saltelli, A.: Sensitivity analysis: Could better methods be used?, J. Geophys. Res., 104, 3789-3793, doi:10.1029/1998JD100042, 1999.

Saltelli, A., Ratto, M., Andres, T., Campolongo, F., Cariboni, J., Gatelli, D., Saisana, M., and Tarantola, S.: Global sensitivity analysis: the primer, John Wiley \& Sons, Inc., 2008.

Saltelli, A., Annoni, P., Azzini, I., Campolongo, F., Ratto, M., and Tarantola, S.: Variance based sensitivity analysis of model output. Design and estimator for the total sensitivity index, Comput. Phys. Commun., 181, 259-270, doi:10.1016/j.cpc.2009.09.018, 2010.

Schwalm, C. R., Huntinzger, D. N., Michalak, A. M., Fisher, J. B., Kimball, J. S., Mueller, B., Zhang, K., and Zhang, Y.: Sensitivity of inferred climate model skill to evaluation decisions: a case study using CMIP5 evapotranspiration, Environ. Res. Lett., 8, 024028, doi:10.1088/1748-9326/8/2/024028, 2013.

Sung, J. H., Kang, H.-S., Park, S., Cho, C., Bae, D. H., and Kim, Y.-O.: Projection of Extreme Precipitation at the end of 21st Century over South Korea based on Representative Concentration Pathways (RCP), Atmosphere, 22, 221-231, doi:10.14191/Atmos.2012.22.2.221, 2012.

Tabari, H.: Evaluation of Reference Crop Evapotranspiration Equations in Various Climates, Water Resour. Manag., 24, 23112337, doi:10.1007/s11269-009-9553-8, 2010.

Tabari, H., Grismer, M. E., and Trajkovic, S.: Comparative analysis of 31 reference evapotranspiration methods under humid conditions, Irrig. Sci., 31, 107-117, doi:10.1007/s00271-011-0295-z, 2013.

Taylor, I. H., Burke, E., McColl, L., Falloon, P. D., Harris, G. R., and McNeall, D.: The impact of climate mitigation on projections of future drought, Hydrol. Earth Syst. Sci., 17, 2339-2358, doi:10.5194/hess-17-2339-2013, 2013.

Taylor, K. E., Stouffer, R. J., and Meehl, G. A.: An Overview of CMIP5 and the Experiment Design, B. Am. Meteorol. Soc., 93, 485-498, doi:10.1175/BAMS-D-11-00094.1, 2012.

Tebaldi, C., Smith, R. L., Nychka, D., and Mearns, L. O.: Quantifying Uncertainty in Projections of Regional Climate Change: A Bayesian Approach to the Analysis of Multimodel Ensembles, J. Climate, 18, 1524-1540, doi:10.1175/JCLI3363.1, 2005.

Teutschbein, C. and Seibert, J.: Bias correction of regional climate model simulations for hydrological climate-change impact studies: Review and evaluation of different methods, J. Hydrol., 456457, 12-29, doi:10.1016/j.jhydrol.2012.05.052, 2012.

Thom, A. S., Thony, J.-L., and Vauclin, M.: On the proper employment of evaporation pans and atmometers in estimating potential transpiration, Q. J. R. Meteorol. Soc., 107, 711-736, doi:10.1002/qj.49710745316, 1981.

Thomas, A.: Spatial and temporal characteristics of potential evapotranspiration trends over China, Int. J. Climatol., 20, 381-396, 2000.

Thompson, J. R., Green, A. J. and Kingston, D. G.: Potential evapotranspiration-related uncertainty in climate change impacts on river flow: An assessment for the Mekong River basin, J. Hydrol., 510, 259-279, doi:10.1016/j.jhydrol.2013.12.010, 2014.

Walsh, J., Wuebbles, D., Hayhoe, K., Kossin, J., Stephens, G., Thorne, P., Vose, R., Wehner, M., Willis, J., Anderson, D., Doney, 
S., Feely, R., Hennon, P., Kharin, V., Knutson, T., Landerer, F., Lenton, T., Kennedy, J., and Somerville, R.: Ch. 2: Our Changing Climate, Climate Change Impacts in the United States: The Third National Climate Assessment, 2014.

Wang, W., Xing, W., Shao, Q., Yu, Z., Peng, S., Yang, T., Yong, B., Taylor, J., and Singh, V. P.: Changes in reference evapotranspiration across the Tibetan Plateau: Observations and future projections based on statistical downscaling, J. Geophys. Res.-Atmos., 118, 4049-4068, doi:10.1002/jgrd.50393, 2013.

Wang, W., Xing, W., and Shao, Q.: How large are uncertainties in future projection of reference evapotranspiration through different approaches?, J. Hydrol., 524, 696-700, doi:10.1016/j.jhydrol.2015.03.033, 2015.

Watanabe, S., Hajima, T., Sudo, K., Nagashima, T., Takemura, T., Okajima, H., Nozawa, T., Kawase, H., Abe, M., Yokohata, T., Ise, T., Sato, H., Kato, E., Takata, K., Emori, S., and Kawamiya, M.: MIROC-ESM 2010: model description and basic results of CMIP5-20c3m experiments, Geosci. Model Dev., 4, 845-872, doi:10.5194/gmd-4-845-2011, 2011.

Wood, A. W., Maurer, E. P., Kumar, A., and Lettenmaier, D. P.: Long-range experimental hydrologic forecasting for the eastern United States, J. Geophys. Res., 107, 4429, doi:10.1029/2001JD000659, 2002.

Wood, A. W., Leung, L. R., Sridhar, V., and Lettenmaier, D. P.: Hydrologic implications of dynamical and statistical approaches to downscaling climate model outputs, Climate Change, 62, 189216, doi:10.1023/B:CLIM.0000013685.99609.9e, 2004.

Xiao-Ge, X., Tong-Wen, W., Jiang-Long, L., Zai-Zhi, W., Wei-Ping, L., and Fang-Hua, W.: How well does BCC-CSM1. 1 reproduce the 20th century climate change over China?, Atmos. Ocean. Sci. Lett., 6, 21-26, 2013.
Xing, W., Wang, W., Shao, Q., Peng, S., Yu, Z., Yong, B., and Taylor, J.: Changes of reference evapotranspiration in the Haihe River Basin: Present observations and future projection from climatic variables through multi-model ensemble, Global Planet. Change, 115, 1-15, doi:10.1016/j.gloplacha.2014.01.004, 2014.

$\mathrm{Xu}$, C. and Singh, V. P.: Evaluation and generalization of temperature-based methods for calculating evaporation, Hydrol. Process., 15, 305-319, doi:10.1002/hyp.119, 2001.

$\mathrm{Xu}, \mathrm{C}$. and Singh, V.: Cross comparison of empirical equations for calculating potential evapotranspiration with data from Switzerland, Water Resour. Manag., 16, 197-219, doi:10.1023/A:1020282515975, 2002.

$\mathrm{Xu}$, C., Gong, L., Jiang, T., Chen, D., and Singh, V. P.: Analysis of spatial distribution and temporal trend of reference evapotranspiration and pan evaporation in Changjiang (Yangtze River) catchment, J. Hydrol., 327, 81-93, doi:10.1016/j.jhydrol.2005.11.029, 2006.

Yukimoto, S., Adachi, Y., Hosaka, M., Sakami, T., Yoshimura, H., Hirabara, M., Tanaka, T. Y., Shindo, E., Tsujino, H., Deushi, M., Mizuta, R., Yabu, S., Obata, A., Nakano, H., Koshiro, T., Ose, T., and Kitoh, A.: A New Global Climate Model of the Meteorological Research Institute: MRI-CGCM3 -Model Description and Basic Performance, J. Meteorol. Soc. Jpn., 90A, 23-64, doi:10.2151/jmsj.2012-A02, 2012.

Zhao, L., Xia, J., Xu, C., Wang, Z., Sobkowiak, L., and Long, C.: Evapotranspiration estimation methods in hydrological models, J. Geogr. Sci., 23, 359-369, doi:10.1007/s11442-013-10159, 2013. 